Uma abordagem flexível para exploração da reutilização de dados on-chip orientada ao padrão de acesso à memória 



\title{
Uma abordagem flexível para exploração da reutilização de dados on-chip orientada ao padrão de acesso à memória
}

\author{
Arnaldo César dos Santos
}

Orientador: Prof. Dr. Vanderlei Bonato

Dissertação apresentada ao Instituto de Ciências Matemáticas e de Computação - ICMC - USP, como parte dos requisitos para obtenção do título de Mestre em Ciências - Ciências de Computação e Matemática Computacional. EXEMPLAR DE DEFESA 

Dedico este trabalho a minha querida mãe Maria e a minhas irmãs Renata e Daniela. 



\section{Agradecimentos}

Agradeço primeiramente a Deus.

Agradeço ao meu orientador, Prof. Dr. Vanderlei Bonato, pelos valiosos conselhos, amizade e paciência durante todo o mestrado.

Agradeço ao meus amigos do LCR, especialmente ao Jean e ao Bruno, pela grande ajuda e companheirismo.

Agradeço aos professores do grupo SEE, Dr. Alexandre Botazzo Delbem e Dr. Cláudio Toledo, que tanto me ajudaram neste trabalho.

Agradeço a minha família, que sempre esteve presente, orando por mim. 

Success is not the key to happiness. Happiness is the key to success. If you love what you are doing, you will be successful.

Albert Schweitzer 



\section{Resumo}

Aplicações de dados intensivos precisam acessar uma grande quantidade de dados armazenados em memórias off-chip. Devido ao dispendioso tempo de acesso, muitos autores propõem arquiteturas que implementam sistemas tais como cache e Scratch-pad Memories (SPM) para otimizar a reutilização de dados. Algumas vezes a SPM pode ser mais adequada que a memória cache, especialmente quando o elemento de processamento é customizado para a aplicação. No entanto, é necessário definir qual é o melhor tamanho da memória e qual e quando um conjunto de dados deve ser carregado na memória. Neste contexto, é desejável desenvolver uma técnica que possa gerar estes valores automaticamente. Este trabalho apresenta uma técnica para minimizar o número de acessos off-chip e o tamanho da memória on-chip (SPM) usada em aplicações baseadas em FPGA. A técnica desenvolvida é baseada em algoritmos genéticos devido à sua flexibilidade para explorar todo o espaço de projeto e fornecer um conjunto de soluções válidas. Ao usar a abordagem, é possivel gerar soluções válidas para loops regulares e função de endereçamento afim (affine). Por exemplo, para a aplicação Sobel nossa técnica foi capaz de encontrar um padrão de acesso que forneceu 83,3\% de redução aos acessos à memória off-chip usando menos de $1 \mathrm{~KB}$ de memória on-chip. 


\section{Abstract}

Data-intensive applications need to access a large amount of data stored in off-chip memories. Due to the expensive offchip access time, several authors propose architectures which implement on-chip memory systems such as cache memories or Scratch-pad Memories (SPM) to optimize the data reuse. Sometimes the SPM can be more suitable than the cache memory, specially when the processing element is customized for the application. However, it is necessary to define what is the best size of the memory and which and when a set of data must be loaded into the memory. In this context, it is desirable to develop a technique that can generate these values automatically. This work present a technique to minimize the number of off-chip accesses and the size of the on-chip memory (SPM) used in FPGA-based applications. The developed technique is based on genetic algorithms due to their flexibility to explore the whole design space and provide a set of valid solutions. By using our approach, it is possible to generate valid solutions for both regular and irregular loops, and for affine and non-affine address functions. For instance, for the Sobel application our technique was able to find an access pattern that provided $83.3 \%$ of reduction to the off-chip memory accesses using less than $1 \mathrm{~KB}$ of on-chip memory. 



\section{Lista de Figuras}

2.1 Relação entre as tecnologias - Adaptada de Tessier e Burleson (2001); Bobda (2007) . . . . . . . . . . . . . . . . . . . .

2.2 Relação entre o tempo e o custo de desenvolvimento em oposição a fatores que influenciam a escolha entre as tecnologias - Adaptada de Hamblen et al. (2008) . . . . . . . . . . . . . . . . . . 7

2.3 Estrutura básica de um FPGA (Adaptada de Bobda (2007)) . . . . . 8

2.4 Implementação de uma função utilizando um LUT de 3 entradas . 9

2.5 O Elemento Lógico (LE) da família Cyclone II Altera ${ }^{\circledast}$ (Bobda, 2007) 9

2.6 Módulo lógico adaptativo (ALM) do FPGA Stratix II Altera (Bobda, 2007) . . . . . . . . . . . . . . . . . 10

2.7 Fluxo de projeto simplificado em FPGA (Adaptada de Hauck e DeHon (2008)) . . . . . . . . . . . . . . . . . . 13

3.1 Operadores genéticos atuando sobre uma representação inteira (Klop-

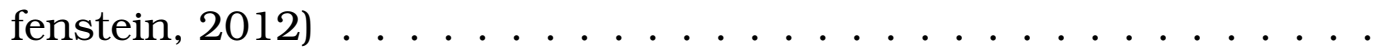

4.1 Diferentes formas de alocação de dados em SPM para a multiplicação de matrizes (Kandemir et al., 2001) . . . . . . . . . . . . . . .

4.2 Exemplo de arquitetura baseada em processador com cache e SPM (Kandemir et al., 2004b) . . . . . . . . . . . . . . . . .

5.1 O exemplo motivacional (EM) e os locais onde é possivel inserir funções de carregamento. A função de checagem é inserida no nível de loop mais interno. . . . . . . . . . . . . . . . .

$5.2 \mathrm{O}$ carregamento e alinhamento dos endereços para a checagem na aplicação EM. Em a), a memória off-chip é representada como uma matriz e cada número representa um endereço. Os elementos em destaque representam os dados carregados na memória on-chip correspondendo ao padrão de dados da aplicação para a primeira iteração do loop mais externo. A parte b) destaca os endereços da memória off-chip alinhados. . . . . . . . . . . . . . . .

5.3 A função load( ), na qual são realizados os carregamentos de dados.

5.4 A função $\operatorname{check}($ ), na qual são realizadas a verificação e o mapeamento de endereços off-chip/on-chip. . . . . . . . . . . . 8

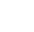
. 3 . 
5.5 O movimento dos dados em duas iterações do loop mais externo da aplicação EM. A parte a) representa a segunda iteração do loop externo. A parte b) representa a terceira iteração do loop, mostrando que a coluna na variável Base permanece fixa na primeira coluna. .

5.6 Representação do cromossomo para o AG. A parte (a) ilustra uma representação genérica de um indivíduo e a parte (b) apresenta um indivíduo para a aplicação EM, mostrada na Figura 5.1. . . . . . . 40

5.7 Núcleo do benchmark QSDPCM. . . . . . . . . . . . . . . . . 42

5.8 Convergência do Algoritmo Genético para a aplicação Sobel. . . . . 43

5.9 O número de acessos à memória off-chip para os benchmarks Sobel e MM64 mostrando uma solução sem reutilização de dados, e outras duas com reutilização de dados, uma para o ótimo local e outra para o ótimo global. . . . . . . . . . . . . . . . .

5.100 número de acessos à memória off-chip para os benchmarks FSME e QSDPCM mostrando uma solução sem reutilização de dados, e outras duas com reutilização de dados, uma para o ótimo local e outra para o ótimo global. Para a solução ótima global as colunas são muito pequenas, uma vez que o ganho obtido é extremamente grande em relação à solução ótima local. . . . . . . . . . . . . . . . .

5.11 Diagrama de blocos do módulo para geração de endereços principal. Este representa a aplicação EM, com três loops aninhados indexados pelas variáveis $\mathrm{i}, \mathrm{j}$ e k . . . . . . . . . . . . .

5.12 Diagrama de blocos do módulo para geração do endereços segundário, que representa a função load( ). . . . . . . . . . . . . .

5.13 Diagrama de bloco do módulo de verificação e mapeamento, que representa a função check( ). . . . . . . . . . . . . . . 


\section{Lista de Tabelas}

3.1 Analogia entre a terminologia utilizada na biologia e em AGs . . . . 16

5.1 Benchmarks utilizados para validação do método proposto. . . . . . 42

5.2 Parâmetros de configuração do Algoritmo Genético para o benchmark Sobel. . . . . . . . . . . . . . . . . . . . . 42

5.3 Elementos lógicos (LEs) e a frequência máxima (FMax) para a arquitetura Sobel. . . . . . . . . . . . . . . . 48 



\section{Lista de Abreviaturas e Siglas}




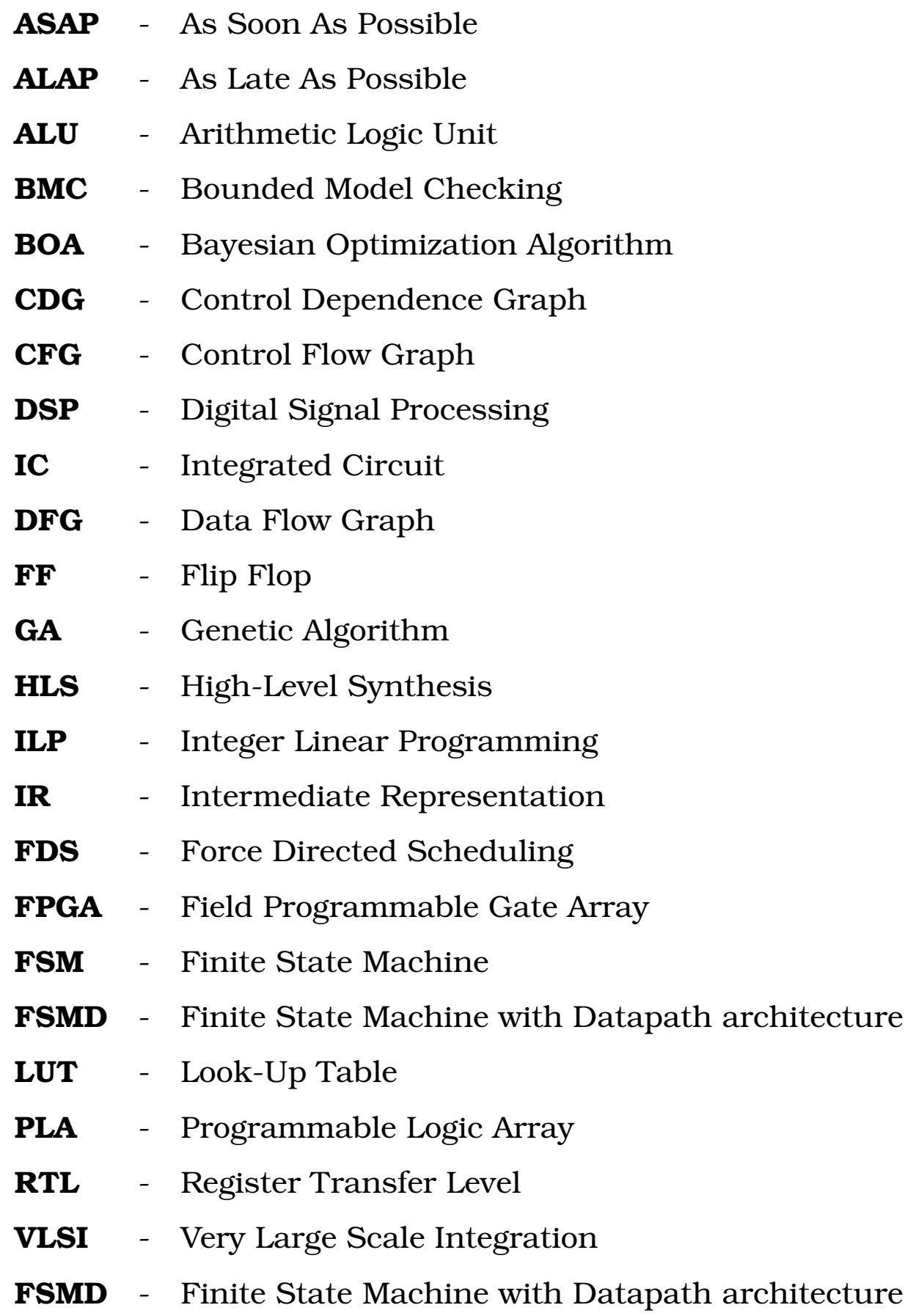





\section{Sumário}

$\begin{array}{ll}\text { Resumo } & \text { i }\end{array}$

$\begin{array}{ll}\text { Abstract } & \text { iii }\end{array}$

1 Introdução $\quad 1$

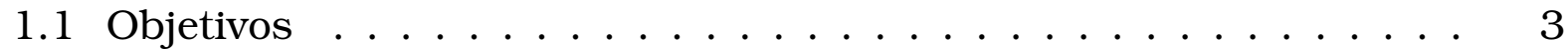

1.2 Contribuições . . . . . . . . . . . . . . . . 4

1.3 Organização da dissertação . . . . . . . . . . . . . . . . . 4

2 Computação Reconfigurável $\quad 5$

2.1 Visão Geral . . . . . . . . . . . . . . . . 5

2.2 Field-Programmable Gate Array (FPGA) . . . . . . . . . . . . . 8

2.3 Sintese RTL . . . . . . . . . . . . . . . . . . . . . 11

2.3.1 Linguagens de Descrição de Hardware . . . . . . . . . . . . . 11

2.3.2 Fluxo de Projeto em FPGA . . . . . . . . . . . . . . 12

3 Algoritmos Evolutivos $\quad 15$

3.1 Algoritmos Genéticos .................... . . 16

3.1.1 Tipos de Representação . . . . . . . . . . . . . . . . 18

3.1 .2 Operadores em AGs . . . . . . . . . . . . . . 19

4 Reutilização de Dados $\quad 23$

4.1 Contextualização . . . . . . . . . . . . . . . . 23

4.1.1 Tipos de Reutilização de Dados . . . . . . . . . . . . . . . 24

4.1.2 Reutilização de Dados em Software . . . . . . . . . . . 25

4.1.3 Reutilização de Dados em Hardware . . . . . . . . . . . . . 26

4.2 Técnicas para Reutilização de Memória . . . . . . . . . . . . . . 28

4.3 Trabalhos Relacionados . . . . . . . . . . . . . . . . . . 29

5 Implementação e Resultados

5.1 Modelagem da Reutilização de Dados . . . . . . . . . . . . . . . . . . 32

5.2 Implementação do Algoritmo Genético

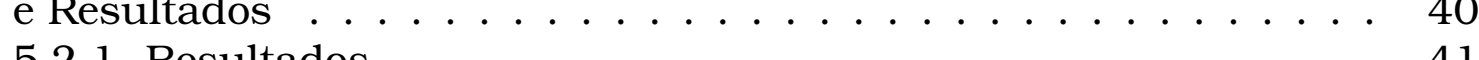

5.3 Projeto da Arquitetura de Hardware . . . . . . . . . . . . . . 45 
6 Conclusões $\quad 49$

6.1 Trabalhos Futuros . . . . . . . . . . . . . . . . 49

$\begin{array}{ll}\text { Referências Bibliográficas } & 54\end{array}$ 


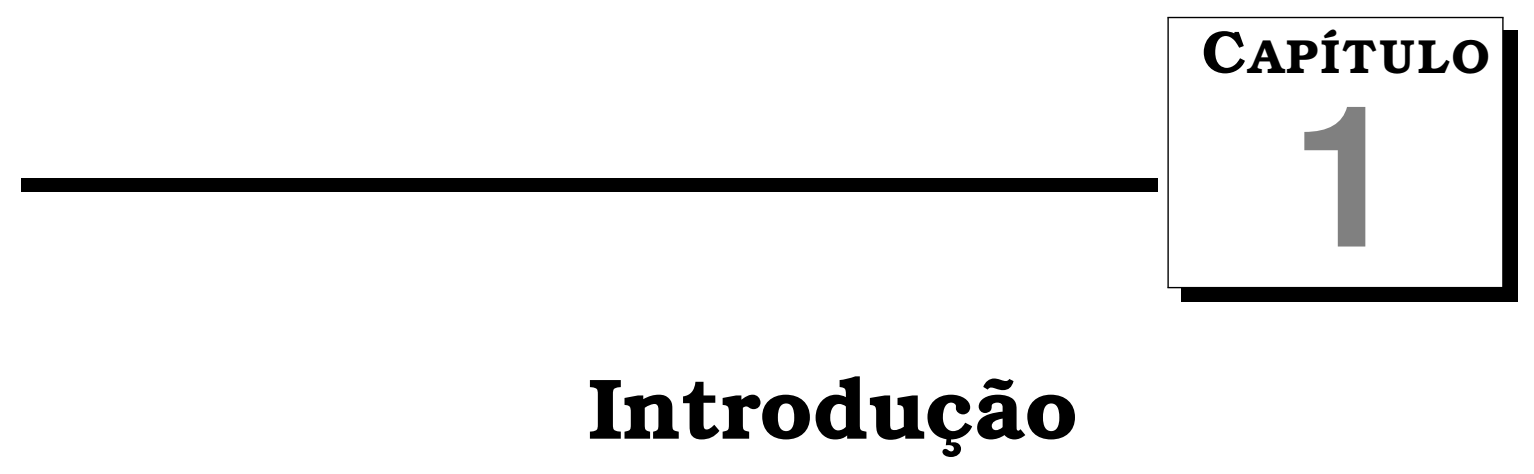

A crescente demanda por dispositivos portáteis e de alto desempenho tem impulsionado as pesquisas na área de sistemas embarcados. Um importante requisito destes sistemas é a relação entre desempenho e consumo de energia. Estes dispositivos são normalmente alimentados por baterias e executam aplicações de alta complexidade computacional.

A maioria das aplicações atuais processam uma grande quantidade de dados, que normalmente são armazenadas em memórias off-chip de grande capacidade, como SDRAMs ${ }^{1}$. Estas aplicações são conhecidas como data-intensive. Entretanto, as memórias off-chip representam um grande gargalo computacional, além de serem as responsáveis por maior parte da energia consumida em sistemas embarcados (Devos et al., 2011a).

A memória cache tem sido o principal dispositivo utilizado na reutilização de dados em processadores de propósito geral (GPPs) e embarcados. Apesar da eficiência das caches, estas memórias não são adequadas para todos os tipos de aplicações. A utilização de buffers on-chip, tal como a Scratch-Pad Memory $\left(\mathrm{SPM}^{2}\right)$ tem se tornado cada vez mais comum em sistemas embarcados (Catthoor e Danckart, 2002). Diferentemente da cache, que possue um controlador em hardware, a SPM é gerenciada pelo desenvolvedor.

Visando acelerar os sistemas e diminuir o consumo de energia, muitas aplicações de computação intensiva (ou data-intensive) têm sido implementadas em hardware dedicado. Além disso, o subsistema de memória têm sido cada vez

\footnotetext{
${ }^{1}$ SDRAM - Synchronous Dynamic Random-Access Memory

${ }^{2}$ SPM - Scratch-Pad Memory
} 
mais explorado para melhorar o desempenho de aplicações, estas implementadas em hardware (ASIC) ou software (GPP) (Catthoor et al., 1998).

A computação reconfigurável vem ganhando espaço entre os projetistas para a implementação de aplicações de alto desempenho. O principal representante deste paradigma, o FPGA, combinam a flexibilidade do software ao desempenho do hardware (Compton e Hauck, 2002).

Embora os FPGAs possibilitem o projeto de arquiteturas de hardware de alto desempenho, são inúmeros os desafios enfrentados pelos projetistas na exploração manual do espaço de projetos. Encontrar uma arquitetura otimizada, a qual cumpra determinados requisitos em relação ao desempenho, área e consumo de energia, em um curto período de projeto não é uma tarefa trivial (Liu et al., 2006). Desta forma, se faz necessário meios para a exploração automática do espaço de projeto. No contexto da computação reconfigurável, SPMs são consideradas como blocos de RAM on-chip e o gerenciamento dos dados deve ser em hardware pelo projetista ou automaticamente, por meio de ferramentas.

Um sistema pode ser implementado de modo a acessar todos os dados diretamente da memória externa (off-chip). Este tipo de configuração é simples de ser implementada e consume poucos recursos on-chip. Porém, o desempenho é baixo e o consumo de energia é elevado. Uma outra possibilidade é armazenar todos os dados necessários a computação em memórias on-chip. Porém, a capacidade de armazenamento deste tipo de recurso é bastante limitada devido ao seu alto custo. Uma solução intermediária é trazer para memória on-chip somente os dados mais utilizados.

No entanto, a modelagem matemática de determinados problemas não é uma tarefa trivial, principalmente considerando uma aplicação real, que concentra um grande número de variáveis, arrays de diversos tamanhos e a distribuição não uniforme de loops regulares e irregulares. O cenário descrito pode levar à uma explosão combinatorial, justificando o emprego de abordagens de otimização alternativas.

Em Liu et al. (2006), este tópico foi abordado, sendo aplicada a reutilização de dados em memórias on-chip do tipo scratch-pad e registradores em sistemas baseados em FPGA. Para resolver este problema, o autor formulou um modelo matemático baseado na Programação Geométrica. Seu trabalho mais recente (Liu et al., 2009b), explora reutilização de dados em conjunto com a paralelização da arquitetura de hardware.

O número de combinações possíveis para a reutilização de dados, levando em consideração o número de loops da aplicação, a quantidade e o tamanho das variáveis (arrays) podem levar a um grande número de combinações. Neste con- 
texto, encontrar a melhor configuração para aumento de desempenho, levando em consideração a limitação dos recursos de memória não é uma tarefa simples.

Algoritmos Evolutivos têm sido utilizados com sucesso em diversos problemas de otimização não triviais. Nesta classe, se destaca o Algoritmo Genético ( $\mathrm{AG}^{3}$ ), que é uma técnicas de busca e otimização inspirados nos mecanismos da evolução e seleção natural. O AG é baseado em populações de soluções, que evoluem pela utilização de determinados operadores (Goldberg, 1989). Há diversas outras técnicas de otimização meta-heurísticas documentadas na literatura, mas em geral precisam de algum conhecimento prévio sobre o espaço de busca do problema. Diferentemente, os AGs permitem a exploração de um grande espaço busca sem precisar de qualquer conhecimento sobre o problema, além de ser uma técnica simples e de fácil implementação.

\subsection{Objetivos}

O objetivo deste trabalho é desenvolver uma técnica para exploração da reutilização de dados on-chip utilizando um Algoritmo Genético (AG). O técnica deve ser parametrizável e permitir encontrar as melhores opções de reutilização para a minimização do número de acessos à memória off-chip, considerando uma restrição de memória on-chip. Por fim, desenvolver uma arquitetura de hardware otimizada para reutilização de dados on-chip em FPGA.

Os objetivos específicos são apresentados a seguir:

- desenvolver um modelo parametrizável capaz de minimizar o número de acessos à memória off-chip;

- desenvolver uma codificação específica para um AG, condizente com os parâmetros do modelo;

- adaptar o modelo como uma função objetivo, considerando restrições de entrada em referentes ao tamanho da memória on-chip;

- validar a técnica utilização de um AG utilizando um conjunto de benchmarks representativos;

- desenvolver uma arquitetura de hardware otimizada para a aplicações contendo loops aninhados;

- desenvolver a arquitetura de hardware da aplicação, com acesso às memórias on-chip (BRAM) e off-chip(SDRAM).

\footnotetext{
${ }^{3} \mathrm{AG}$ - Algoritmo Genético
} 


\subsection{Contribuições}

As principais contribuições deste trabalho são:

- o desenvolvimento de um método simples, direto e parametrizável para a reutilização de dados on-chip, adaptado como uma função objetivo, o qual permite o carregamento e checagem dos dados considerando uma restrição para o tamanho da memória;

- o desenvolvimento de uma codificação específica para otimização heurística de aplicações data-intensive que permite a identificação automática das melhores configurações de carregamento e a alocação ótima de dados na SPM;

- a implementação de uma arquitetura de hardware para a reutilização de dados capaz de gerenciar o dados entre as memórias off-chip (SDRAM) e on-chip(SPM);

\subsection{Organização da dissertação}

Esta dissertação está organizada da seguinte forma:

- O Capítulo 2 apresenta um resumo dos principais conceitos sobre a reutilização de dados, incluindo trabalhos relacionados;

- O Capítulo 3 introduz alguns conceitos importantes de algoritmos evolutivos, bem como detalhes sobre diferentes tipos de codificação de AGs e seus operadores;

- O Capítulo 4 descreve alguns conceitos básicos de Computação Reconfigurável e FPGAs;

- O Capítulo 5 detalha a implementação do AG e da arquitetura de hardware para reutilização de dados, além da apresentação e discussão dos resultados;

- O Capítulo 6 apresenta as conclusões, considerações finais sobre o projeto e sugestões de trabalhos futuros. 
Capítulo 2

\section{Computação Reconfigurável}

\subsection{Visão Geral}

Na computação, há basicamente duas formas para se executar uma aplicação: em hardware, por meio de uma arquitetura dedicada específica para a tarefa (ASIC); ou em software, por meio de um processador de propósito geral (GPP).

O dispositivo ASIC ${ }^{1}$ pode ser descrito com uma arquitetura de hardware fabricada para realizar tarefas específicas (Compton e Hauck, 2002). Apesar destes dispositivos oferecerem alto desempenho e baixo consumo de energia, o projeto não pode ser alterado depois da fabricação (inflexível). Além disso, apresentam um alto custo nas fases de projeto e teste (Khan, 2011).

O processador de propósito geral, ou GPP ${ }^{2}$, pode ser descrito como uma arquitetura genérica projetada para a execução sequencial de instruções. Esta é a plataforma de execução de algoritmos mais popular nos dias atual. A principal vantagem deste é a alta flexibilidade, pois permite modificações na aplicação apenas alterando o software especificado, normalmente implementado utilizando uma linguagem de programação de alto nível. No entanto, o desempenho destas aplicações é muito inferior ao das aplicações específicas em hardware dedicado (Compton e Hauck, 2002).

Além disso, há uma variedade de dispositivos disponíveis para implementação de sistemas embarcados, como por exemplo, os microcontroladores e DSPs

\footnotetext{
${ }^{1}$ ASIC - Application Specific Integrated Circuit

${ }^{2} \mathrm{GPP}$ - General Purpose Processor
} 
(Digital Signal Processor). Estes dispositivos são processadores implementados com funções específicas, que aumentam o desempenho de algumas classes de aplicações.

A computação reconfigurável surgiu como uma opção para preencher a lacuna entre os dispositivos ASIC e GPP, sendo possivel obter um desempenho próximo ao do hardware(ASIC), com a mesma flexibilidade do software (Compton e Hauck, 2002).

O dispositivo reconfigurável mais popular é o FPGA (Field-Programmable Gate Array), embora existam outros, como o PLA (Programmable Logic Array) e o CPLD (Complex Programmable Logic Device). Os FPGAs foram introduzidos no mercado pela empresa Xilinx ${ }^{\circledast}$ em 1986, e desde então crescendo em popularidade na computação.

FPGAs são dispositivos lógicos (re)programáveis que permitem o projeto de sistemas de alta complexidade, podendo ser centenas de vezes mais rápidos e eficientes em termos de energia que os processadores de propósito geral. Também podem ser utilizados na prototipagem rápida de aplicações para ASICs.

A decisão de implementar um sistema em uma determinada plataforma, considerando GPPs, microcontroladores, DSPs, ASICs ou FPGAs, deve ser tomada com base na complexidade computacional da tarefa, na densidade do código, na comunicação com outras tarefas e no time-to-market (Khan, 2011). A Figura 2.1 ilustra a relação entre as tecnologias.

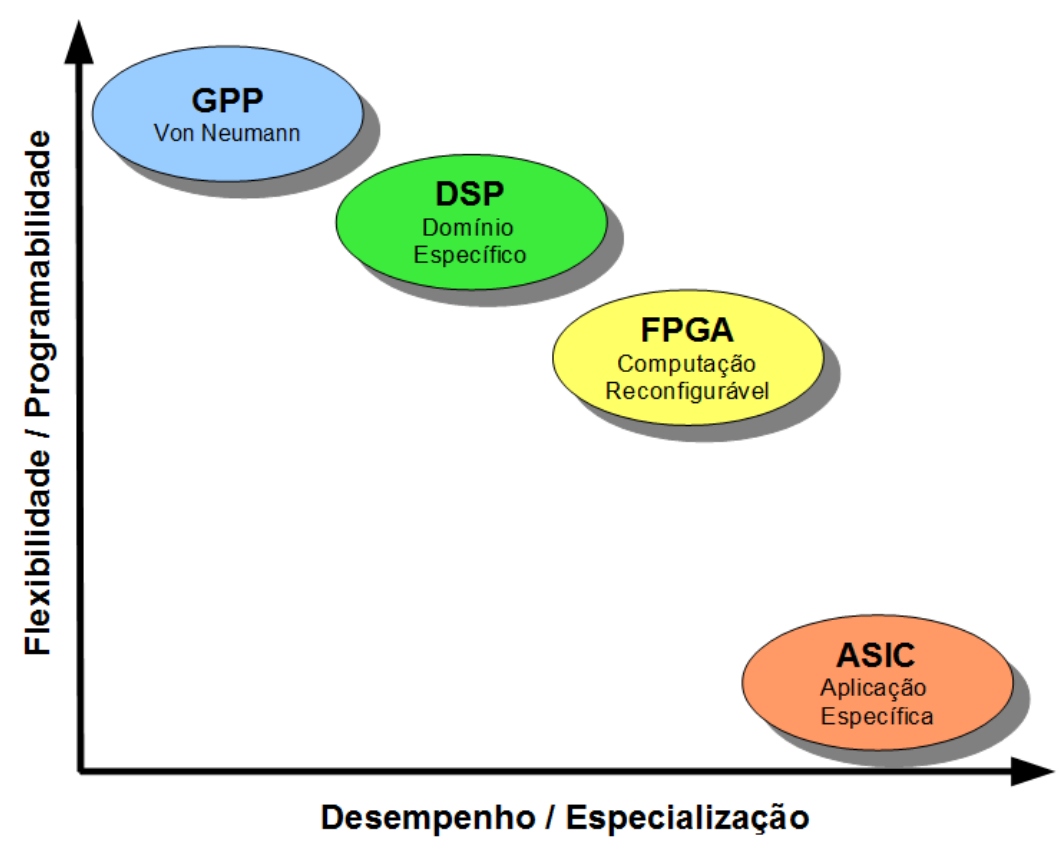

Figura 2.1: Relação entre as tecnologias - Adaptada de Tessier e Burleson (2001); Bobda (2007) 
Quanto ao projeto de arquiteturas de hardware, este pode ser divido em dois seguimentos: VLSI (produção em larga escala) e ASIC (produção em escala moderada). A tecnologia VLSI ${ }^{3}$ (totalmente customizada), que é projetada em nível de transistores, costuma ser empregada na fabricação de dispositivos com microprocessadores e memórias. Os projetos desenvolvidos com esta tecnologia são complexos e costumam demorar anos ao custo de milhões. Embora o projeto de ASICs também seja inflexível, seu custo e tempo de desenvolvimento são menores que no projeto VLSI (Hamblen et al., 2008). Um projeto ASIC costuma ser desenvolvido para uma aplicação específica e sua produção realizada em larga escala. Por exemplo, os chips encontrados em Mp3 players, telefones celulares e smartphones podem ser utilizados por diferentes montadoras e podem ser originários de um único lote de ASICs. A Figura 2.2 ilustra um gráfico com o tempo e o custo de desenvolvimento de diferentes tecnologias em relação a alguns fatores, como velocidade e volume de mercado necessário para a produção, que podem influenciar a escolha da tecnologia para o desenvolvimento do projeto. A principal vantagem dos FPGAs é a possibilidade de reconfiguração do dispositivo, durante todo o ciclo de projeto(Tessier e Burleson, 2001; Hauck e DeHon, 2008). Embora a velocidade de aplicações projetadas em FPGA ainda seja inferior a de aplicações em ASIC, a utilização destes dispositivos tem sido cada vez mais comum na indústria e difundida no meio acadêmico (Bobda, 2007).

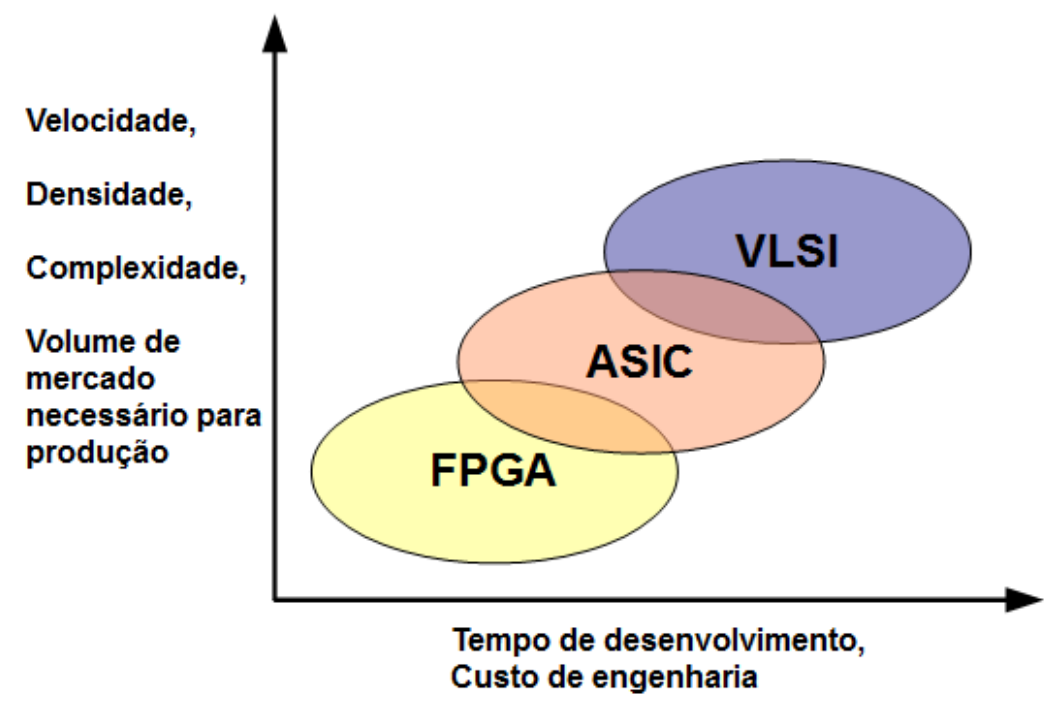

Figura 2.2: Relação entre o tempo e o custo de desenvolvimento em oposição a fatores que influenciam a escolha entre as tecnologias - Adaptada de Hamblen et al. (2008)

\footnotetext{
${ }^{3}$ VLSI - Very Large Scale Integration
} 


\subsection{Field-Programmable Gate Array (FPGA)}

FPGAs são formados por um conjunto de blocos lógicos configuráveis, os quais podem ser utilizados para implementar qualquer função lógica. A programabilidade dos FPGAs é garantida pela combinação de três componentes principais: os blocos lógicos configuráveis $\left(\mathrm{CLBs}^{4}\right)$, os blocos de entrada e saída ( $\mathrm{IOBs}^{5}$ ) e as chaves de interconexão (Bobda, 2007). A Figura 2.3 ilustra a estrutura básica de um FPGA.

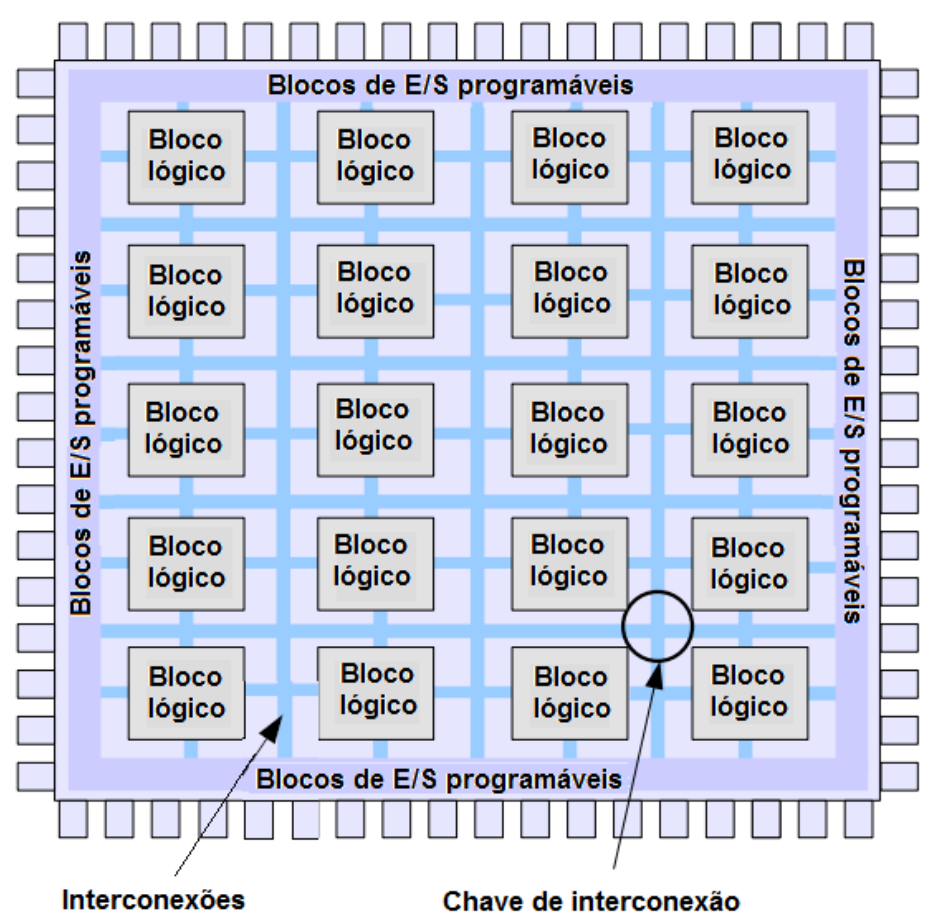

Figura 2.3: Estrutura básica de um FPGA (Adaptada de Bobda (2007))

As funções lógicas implementadas pelo CLB são realizadas por um dispositivo de memória programável, chamado Lookup Table (LUT) (Tessier e Burleson, 2001). Um LUT é formado por um conjunto de células de memória que podem conter todos os possiveis resultados de uma determinada função para um determinado conjunto de valores de entrada. Normalmente, este conjunto de valores corresponde a todas as possíveis combinações das entradas. Por exemplo, um LUT de $n$ entradas pode implementar até $2^{2^{n}}$ funções diferentes. Portanto, este deve fornecer $2^{n}$ células de armazenamento. Nos FPGAs, um LUT consiste de um conjunto de células SRAM para armazenar os valores e um decodificador que é usado para acessá-las corretamente, obtendo o resultado que corresponde à combinação de entrada (Bobda, 2007). A Figura 2.4(a) ilustra a tabela-verdade

\footnotetext{
${ }^{4}$ CLB - Configurable Logic Block

${ }^{5} \mathrm{IOB}$ - Input Output Block
} 
de uma função, e a Figura 2.4(b) um LUT de três portas e a implementação da função exemplificada.

\begin{tabular}{ccc|c}
\hline$x$ & $y$ & $z$ & $x y+z$ \\
\hline 0 & 0 & 0 & 1 \\
0 & 0 & 1 & 0 \\
0 & 1 & 0 & 1 \\
0 & 1 & 1 & 0 \\
1 & 0 & 0 & 1 \\
1 & 0 & 1 & 0 \\
1 & 1 & 0 & 1 \\
1 & 1 & 1 & 1
\end{tabular}

(a) Tabela-verdade

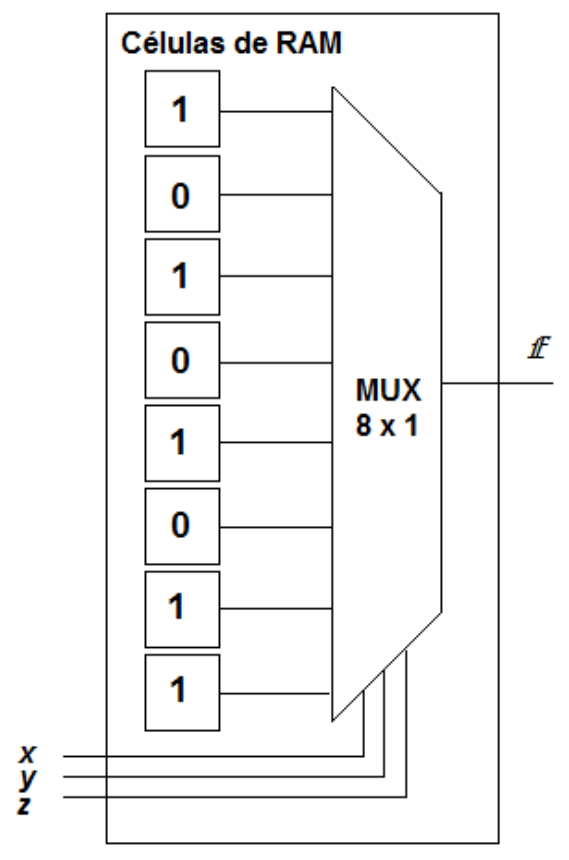

(b) LUT de 3 entradas

Figura 2.4: Implementação de uma função utilizando um LUT de 3 entradas

Os LUTs costumam ser agrupados em unidades lógicas básicas, nas quais estão disponíveis outros elementos funcionais, como flip-flops e multiplexadores (Bobda, 2007). A Figura 2.5 apresenta a estrutura de uma dessas unidades, denominada Elemento Lógico $\left(\mathrm{LE}^{6}\right)$ referente ao FPGA da família Cyclone II Altera ${ }^{\circledast}$.

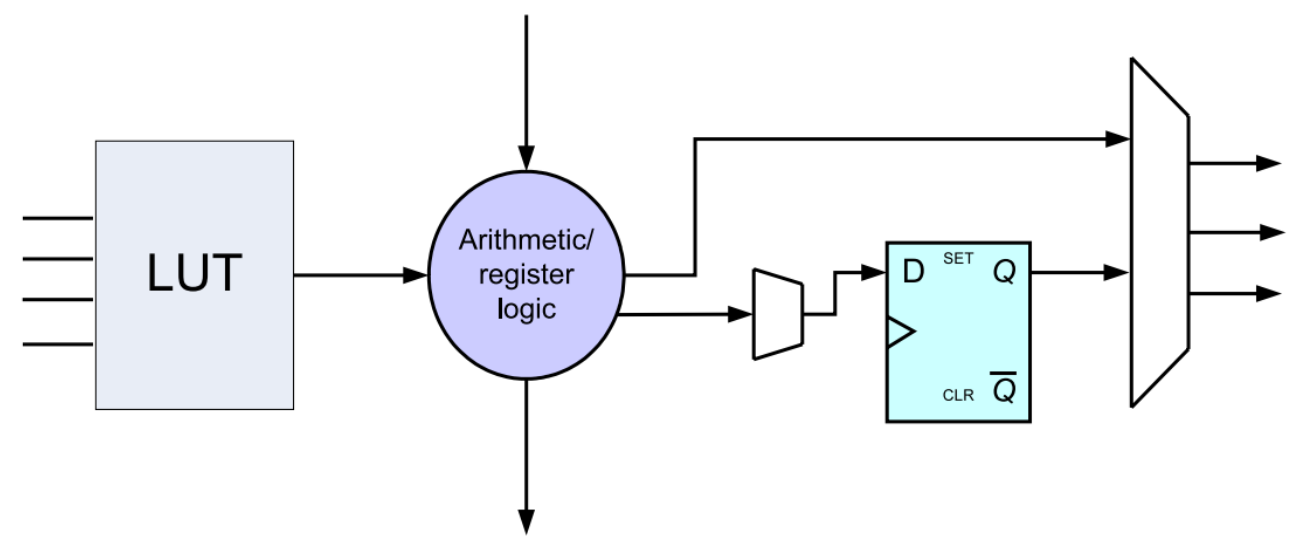

Figura 2.5: O Elemento Lógico (LE) da família Cyclone II Altera ${ }^{\circledast}$ (Bobda, 2007)

A nomenclatura da unidade básica pode variar de acordo com o fabricante ou família de dispositivos. Nos FPGAs da família Stratix Altera ${ }^{\circledR}$ a unidade básica é

${ }^{6} \mathrm{LE}-$ Logic Element 
denominada módulo lógico adaptativo (ALM) ${ }^{7}$. O ALM é possui LUTs de 3 e 4 entradas variadas, possibilitando a implementação de módulos com granularidade grossa (até 8 entradas). A Figura 2.6 ilustra a estrutura interna de um ALM da família de dispositivos Stratix II Altera.

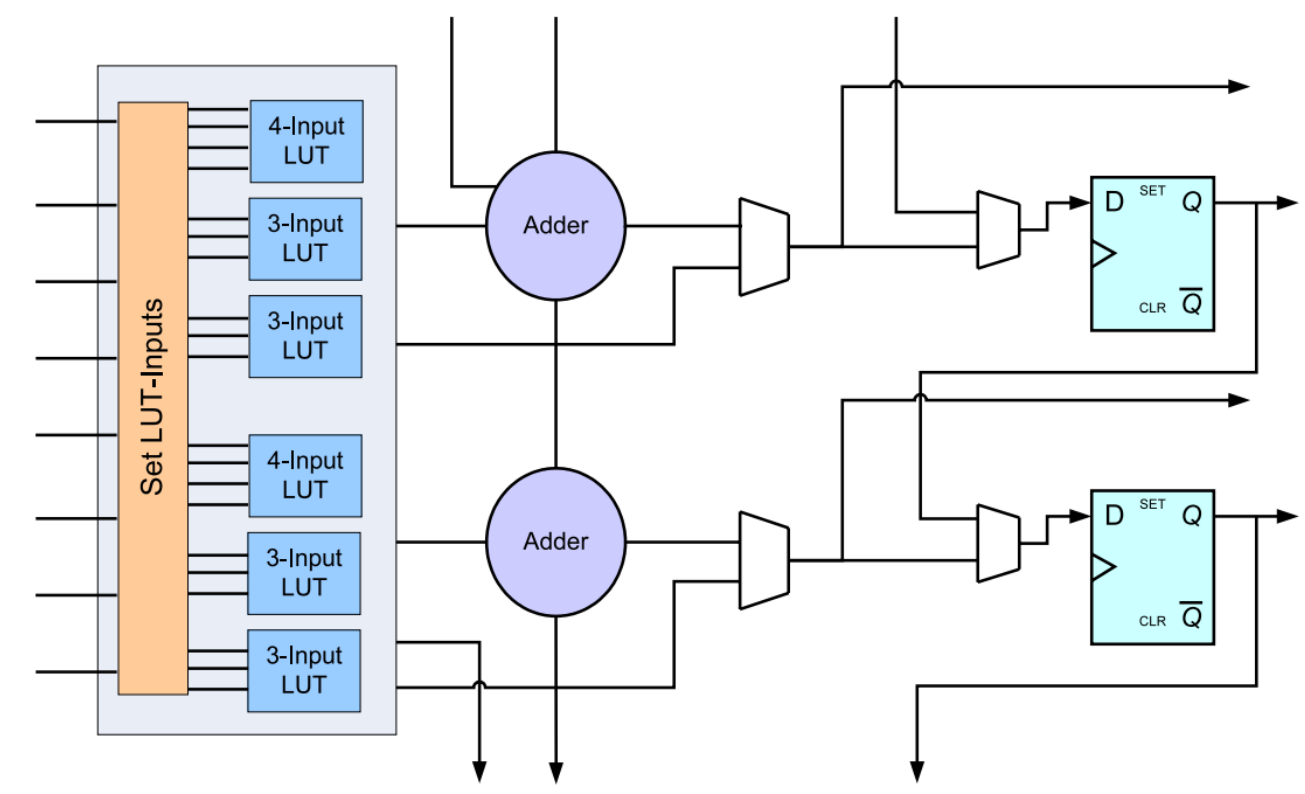

Figura 2.6: Módulo lógico adaptativo (ALM) do FPGA Stratix II Altera (Bobda, 2007)

Os ALMs são agrupados para formar cadeias de blocos lógicos, denominados $\mathrm{LABs}^{8}$. O número de ALMs em cada LAB varia entre os dispositivos. Por exemplo, nos dispositivos da família Cyclone II Altera ${ }^{\circledR}$, cada LAB contém dezesseis LEs.

FPGAs implementam uma forma de computação espacial, ou seja, é possível projetar aplicações que executem milhares de operações simultaneamente em recursos distribuídos pelo chip(Hauck e DeHon, 2008). Para que um projeto em FPGA seja realmente eficiente é preciso explorar o paralelismo e os recursos oferecidos pelo dispositivo. Entretanto, projetar arquiteturas de hardware massivamente paralelas não é uma tarefa trivial.

FPGAs têm sido cada vez mais utilizados para implementar aplicações específicas, como de processamento multimídia, processamento de sinais (DSP), comunicação, entre outras (Hamblen et al., 2008). Para o projeto, são utilizadas ferramentas de compilação e síntese $\left(\mathrm{EDA}^{9}\right)$ Estas ferramentas geram um arquivo para a configuração do dispositivo à partir de especificações de entrada, normalmente utilizando linguagens de descrição de hardware $\left(\mathrm{HDL}^{10}\right)$.

\footnotetext{
${ }^{7} \mathrm{ALM}$ - Adaptative Logic Module

${ }^{8} \mathrm{LAB}$ - Logic Array Blocks

${ }^{9} \mathrm{EDA}$ - Engineering Design Automation

${ }^{10} \mathrm{HDL}$ - Hardware Description Language
} 


\subsection{Síntese RTL}

A configuração dos dispositivos FPGAs normalmente é realizada utilizando uma linguagem de descrição de hardware (HDLs ${ }^{11}$ ), como VHDL ou Verilog, que também são utilizadas no projeto de ASICs. Entende-se por fluxo de projeto tradicional as etapas necessárias para síntese de circuitos digitais utilizando linguagens de descrição de hardware (HDLs).

O projeto de um sistema em hardware utilizando HDLs é mais complexo do que a programação em software, pois o projetista deve especificar o comportamento de cada componente do sistema.

\subsubsection{Linguagens de Descrição de Hardware}

A linguagem de descrição de hardware VHDL (VHSIC ${ }^{12}$ Hardware Description Language) foi criada na década de 80 como uma iniciativa do Departamento de Defesa Americano (U.S) na tentativa de unificar a modelagem das especificações para o projeto de circuitos integrados. Foi padronizada pela IEEE (Institute of Eletrical and Electronic Enginners) em 1987 e, desde então, vem sendo suportada pela maioria das ferramentas de síntese do mercado (Perry, 2002; Ashenden, 2008).

VHDL é baseada na linguagem de programação ADA e possui uma estrutura semântica concorrente, embora tenha algumas abstrações das linguagens de programação orientadas a objeto, como encapsulamento e interfaces. A linguagem utiliza sinais e portas de entrada/saída (in/out) como interface entre os módulos (entity) de hardware de um sistema. No interior de cada módulo é descrita a arquitetura (architecture), que pode conter blocos internos de execução sequencial (process) (Hauck e DeHon, 2008). É possível programar utilizando uma descrição estrutural ou comportamental. A descrição estrutural permite ao projetista gerenciar toda a complexidade do hardware, através da programação de componentes primitivos como portas lógicas e multiplexadores. Na descrição comportamental, ou RTL (Register Transfer Level), a lógica é organizada como transformações de dados entre estágios de registradores. A descrição comportamental é mais simples que a estrutural, porém, o nível de abstração ainda é muito baixo se comparado à programação em software.

Em contraste à linguagem VHDL, Verilog é baseada na linguagem de programação C. Também é suportada pela maioria das ferramentas de sintese, possuindo uma estrutura similar a da linguagem VHDL, embora tenha uma sintaxe

\footnotetext{
${ }^{11} \mathrm{HDL}$ - Hardware Description Language

${ }^{12}$ VHSIC - Very High Speed Integrated Circuits
} 
diferente. Muitas das estruturas presentes na linguagem possuem uma equivalente em VHDL. Por exemplo, a estrutura modular em VHDL, denominada Entity, em Verilog é denominada Module.

Além de VHDL e Verilog, há outras opções para o projeto de hardware, o que inclui a linguagem SystemC. SystemC é uma linguagem de modelagem baseada na linguagem $\mathrm{C}++$. Pode ser usada para modelar um sistema completo, incluindo componentes de hardware e software. A linguagem SystemC decompõe o sistema em um conjunto de módulos, que são conectados usando portas. Desta forma é representada a estrutura do sistema. Uma biblioteca de classes é definida, a qual fornece os componentes usados na construção do sistema. Classes derivadas podem ser usadas para implementar o sistema diretamente usando $\mathrm{C}++$. A funcionalidade é similar à VHDL ou Verilog, onde cada módulo contém processos que executam de forma concorrente, com um código dentro de cada processo executando de forma sequencial. Uma das características de SystemC é a separação da computação da comunicação. Isto permite um movimento para um alto nível de comunicação entre os processos através de uma modelagem em nível transacional $\left(\mathrm{TLM}^{13}\right)$. A linguagem possui tipos de dados orientados para hardware e suporta a aritmética do ponto fixo. Ela elava o nível de abstração das HDLs convencionais. Embora tenha sido primariamente projetada como uma linguagem de modelagem, um subconjunto de SystemC (incluindo em nível comportamental) pode ser sintetizado para implementações para FPGA (SystemC, 2012; Hauck e DeHon, 2008).

\subsubsection{Fluxo de Projeto em FPGA}

As modernas ferramentas de síntese (EDA ${ }^{14}$ ), oferecem todos os recursos necessários para síntese HDL, implementação e programação do dispositivo FPGA. A Figura 2.7 ilustra um fluxo de projeto em FPGA.

O fluxo de projeto em FPGA se inicia com a descrição do circuito utilizando uma HDL, como VHDL ou Verilog (Hauck e DeHon, 2008). À partir do código de entrada HDL, a síntese RTL gera um arquivo denominado netlist, o qual representa uma descrição textual do circuito da aplicação. Em seguida, o netlist é traduzido (translate), mapeado(map), alocado (place) e roteado (route) para a estrutura de hardware.

No mapeamento é realizada a substituição lógica dos componentes do netlist para os blocos lógicos (CLBs) e blocos de entrada e saída (IOBs) do dispositivo FPGA. Nas duas últimas etapas do fluxo, são realizadas a alocação dos recursos

\footnotetext{
${ }^{13}$ TLM - Transaction Level Modeling

${ }^{14} \mathrm{EDA}$ - Engineering Design Automation
} 


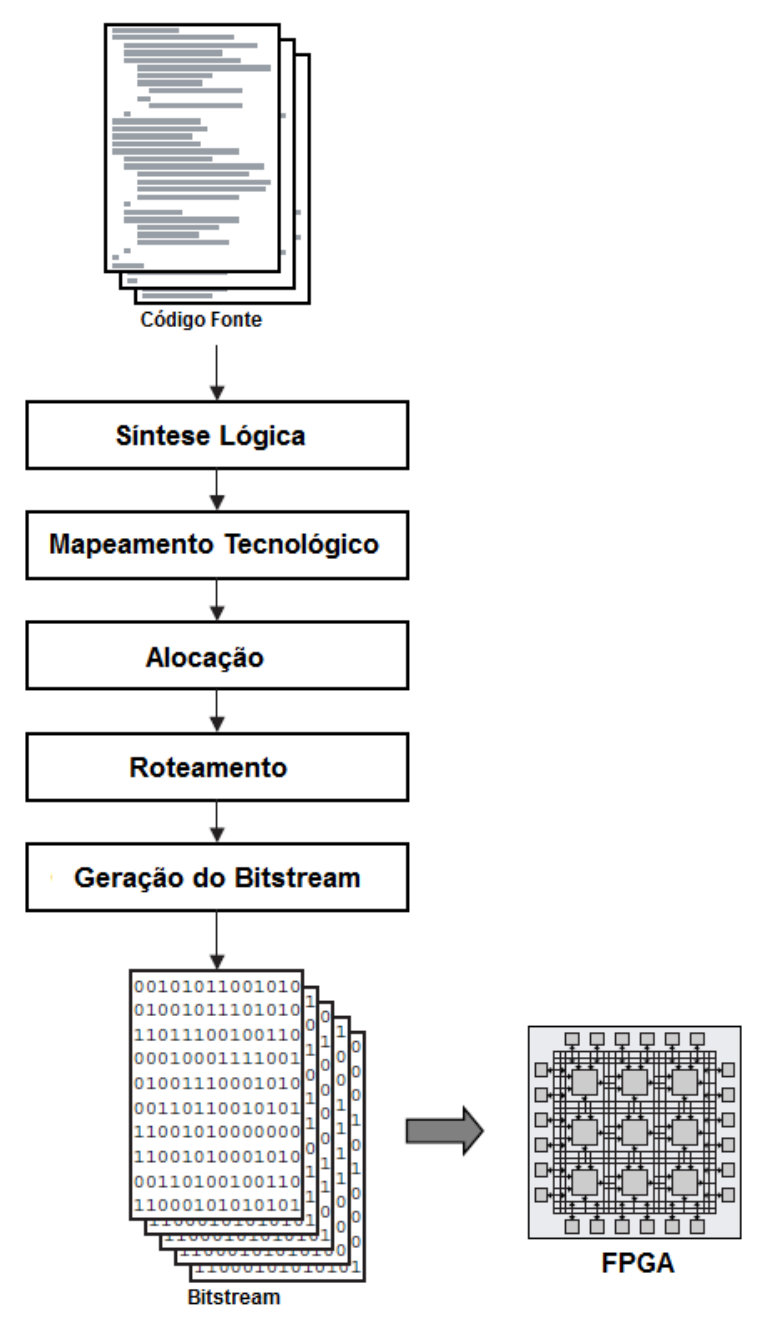

Figura 2.7: Fluxo de projeto simplificado em FPGA (Adaptada de Hauck e DeHon (2008))

e determinadas as rotas de interligação do circuito. Ao final do fluxo é gerado um arquivo, denominado bitstream, que é carregado no dispositivo FPGA.

No entanto, durante as etapas do fluxo de projeto alguns problemas podem ocorrer, tal como o projeto não poder ser implementado devido as restrições de recursos do dispositivo ou problemas relacionados à temporização.

Na fase de pré-projeto, um recurso importante é a simulação (comportamental e/ou funcional). Muitas vezes, a simulação é o único recurso disponível para depuração do projeto da aplicação. 



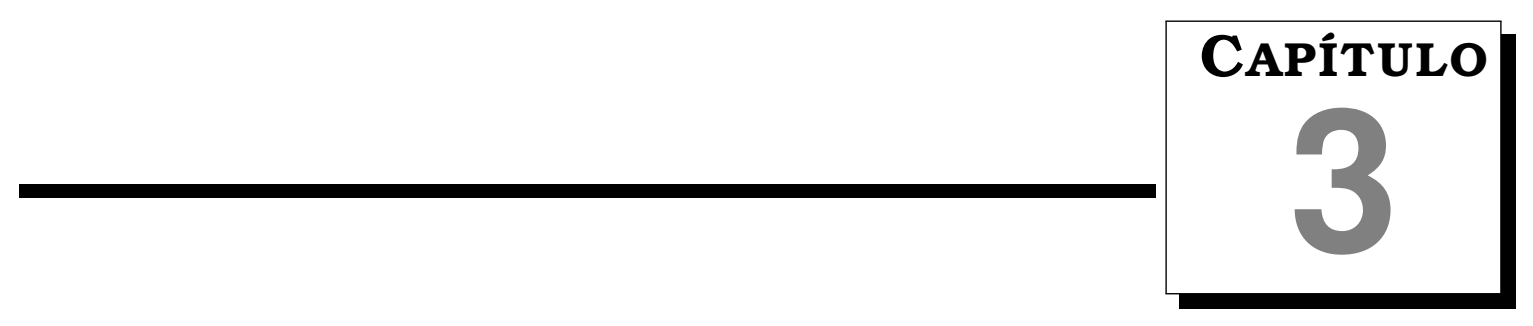

\section{Algoritmos Evolutivos}

Segundo Darwin (1859), na natureza há uma competição por recursos entre os indivíduos de uma população. Este fato acaba por selecionar os indivíduos, onde os menos aptos têm menos chances de sobreviverem e se reproduzirem. Enquanto isso, os mais aptos sobrevivem e geram descendentes, transmitindo suas boas características para seus descendentes. O resultado após algumas gerações é a evolução das espécies, tornando-as mais adaptadas ao ambiente.

A Computação Evolutiva abstrai os princípios da evolução das espécies em Algoritmos Evolutivos, que podem ser utilizados na busca por soluções ótimas para um determinado problema (Sivanandam e Deepa, 2007).

O que distingue um Algoritmo Evolutivo de um método de busca tradicional é o fato do primeiro ser baseado em uma população de soluções. Os métodos de otimização tradicionais não são robustos o suficiente para suportar mudanças que possam ocorrer dinamicamente no ambiente. Ao contrário, os Algoritmos Evolutivos e sua população de soluções fornecem meios para adaptação frente as mudanças (Sivanandam e Deepa, 2007). Além disso, estes algoritmos não utilizam as bases matemáticas encontradas em problemas de otimização, precisando apenas de uma forma de avaliação e de uma função objetivo.

São várias a ramificações da Computação Evolutiva. Segundo Reeves e Rowe (2003), os Algoritmos Evolutivos podem ser classificados da seguinte maneira: Algoritmos Genéticos, Estratégias Evolutiva, Programação Evolutiva, Programação Genética, Vida Artificial e Hardware Evolutivo. Neste trabalho será utilizado o Algoritmo Genético, descrito em detalhes na próxima seção. 


\subsection{Algoritmos Genéticos}

Os Algoritmos Genéticos (AGs) são técnicas de busca e otimização estocásticas inspiradas em elementos da biologia evolutiva (Goldberg, 1989). Os AGs foram iniciados por Holland (1975), que descreveu como aplicar os princípios da evolução natural em problemas de otimização. Sua técnica incluía a utilização dos operadores de recombinação e mutação para melhorar o desempenho, além de uma base teórica conhecida como teorema dos esquemas (Haupt e Haupt, 2004).

Segundo Sivanandam e Deepa (2007), os AGs apresentam algumas características interessantes, como:

- Aleatoriedade: essencial na seleção e reprodução dos indivíduos;

- Base Populacional: consideram uma população de soluções, podendo recombinálas para obter as melhores. Além disso, uma base populacional armazenada na memória favorece a paralelização.

Apesar de haver nenhuma garantia que um AG encontre a melhor solução para um problema (ótimo global), muitas vezes encontrar uma solução aproximada pode ser uma opção interessante, principalmente em problemas difíceis de natureza combinatorial.

A recombinação, ou reprodução sexual, é a característica chave da evolução natural. Na biologia, a forma mais comum de recombinação é o crossover, onde dois cromossomos são divididos em um ponto e as duas metades são unidas para criar novos cromossomos. O efeito desta recombinação é muito importante, pois permite que as características de dois genitores sejam passados para seus descendentes. Se as características forem boas, a nova geração poderá produzir indivíduos melhores, levando à uma evolução gradativa das espécies. Os Algoritmos Genéticos seguem o mesmo princípio da evolução natural, com cada cromossomo representando uma possível solução para o problema. A Tabela 3.1 faz uma analogia entre a terminologia utilizada na biologia e em AGs.

Tabela 3.1: Analogia entre a terminologia utilizada na biologia e em AGs

\begin{tabular}{lc}
\hline Evolução Natural & Algoritmo Genético \\
\hline \hline Cromossomo & Lista valorada ou String de caracteres \\
Gene & Característica ou Conjunto de caracteres \\
Alelo & Valor da característica ou Caractere \\
Locus & Posição na Lista ou Índice na String \\
Genótipo & Estrutura codificada \\
Fenótipo & Conjunto de parâmetros ou Estrutura decodificada \\
\hline
\end{tabular}


A mutação é uma forma de se obter novos genomas, por meio da alteração do valor dos genes. Mesmo na natureza, a operação de mutação não é muito frequente (Sivanandam e Deepa, 2007). Em AGs, algumas mudanças aleatórias podem ser úteis na exploração do espaço de busca. A probabilidade do algoritmo convergir para uma solução mediana (ótimo local) é alta. Desta forma, a utilização do operador de mutação em alguns indivíduos após a recombinação adiciona um grau de diversidade à população, diminuindo a probabilidade de convergência para ótimos locais. Porém, se muitos indivíduos forem submetidos ao operador de mutação corre-se o risco do algoritmo se tornar uma busca aleatória.

A Figura 3.1(a) ilustra de forma simplificada as operações de crossover e mutação em cromossomos representados por número inteiros. Na Figura 3.1(b) é mostrado um possível efeito da mutação em algoritmos que tendem a convergir para ótimos locais.

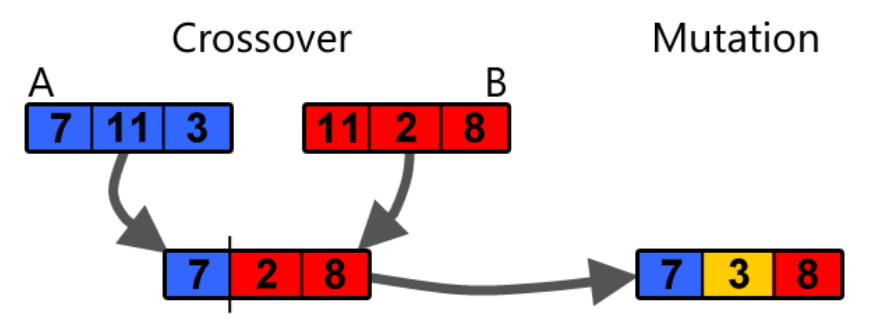

(a) Crossover e mutação

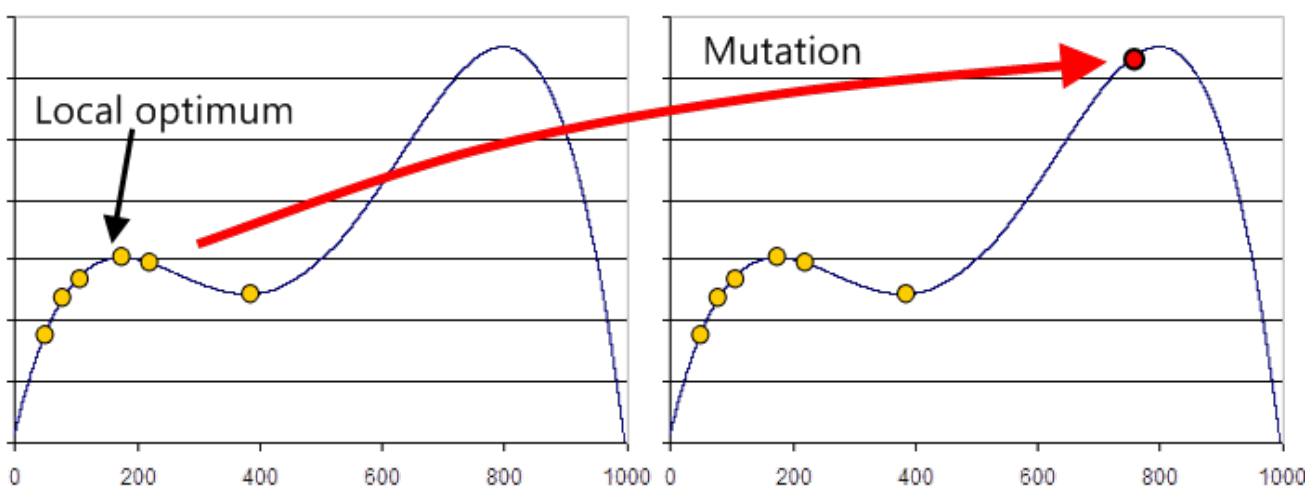

(b) Efeito da mutação no AG

Figura 3.1: Operadores genéticos atuando sobre uma representação inteira (Klopfenstein, 2012)

O Algoritmo 3.1 apresenta o funcionamento de um AG básico. Como pode ser observado, o operador de seleção antecede os operadores de recombinação (crossover) e mutação. Estes e outros operadores serão detalhados à seguir. 


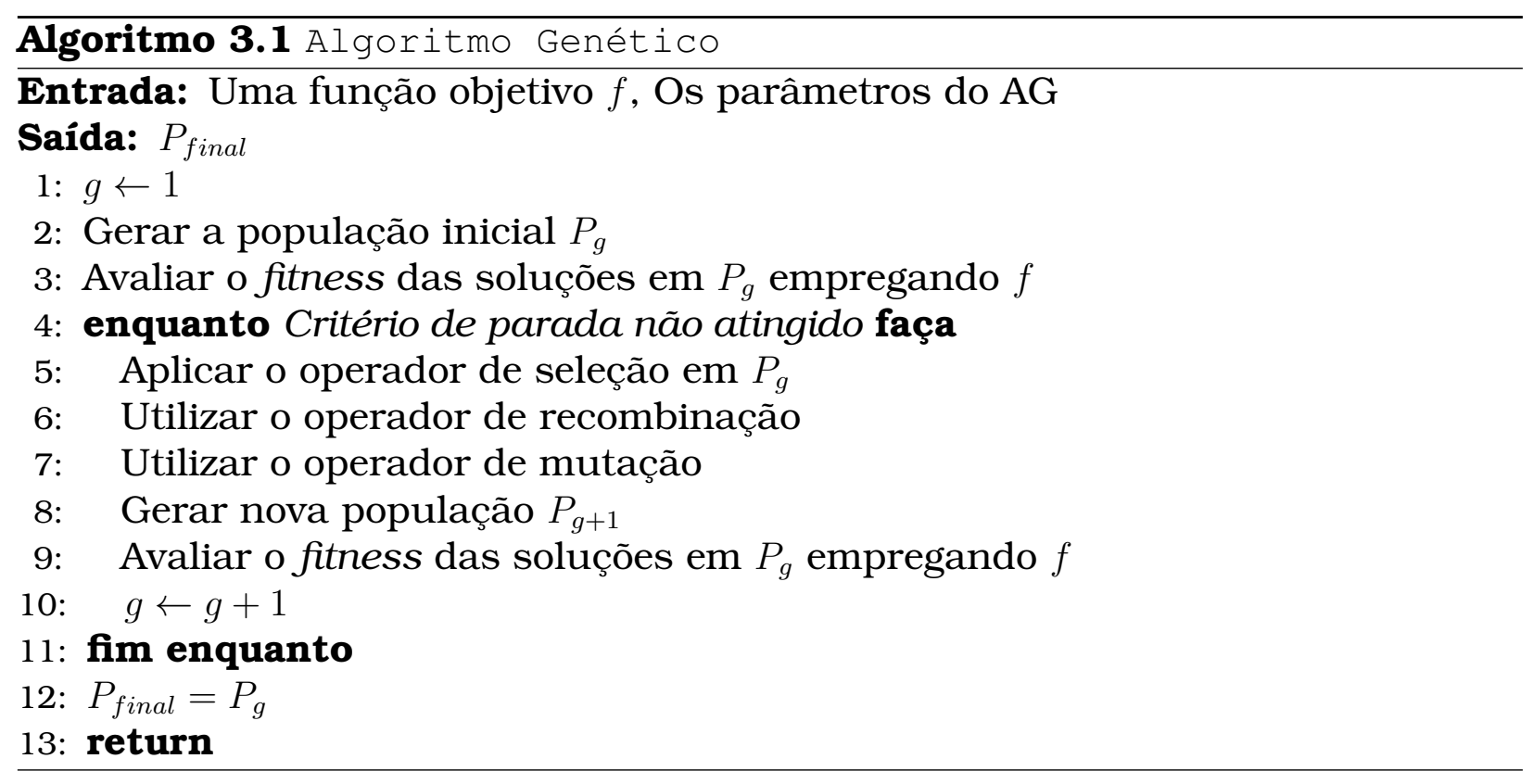

\subsubsection{Tipos de Representação}

Segundo Jong (2006), a eficiência de um algoritmo evolutivo depende dos operadores de seleção aplicados a uma representação adequada e uma inicialização. Algoritmos evolutivos podem ser aplicados em qualquer problema que possa ser formulado como uma função. Para resolver esta função é necessário uma estrutura de dados para representar uma solução. A representação também permite, pela variação dos operadores, que seja mantida uma ligação entre os pais e seus descendentes.

São várias as representações possíveis em AGs. Por exemplo, é possível representar os indivíduos como matrizes, árvores e símbolos. Escolher uma representação adequada é uma tarefa importante para AGs (Deb, 2001). Entretanto, as formas mais comuns de representação ainda são as binárias e contínuas.

\section{Representação Binária}

A representação binária é a mais comum em AGs, porém, se as variáveis são contínuas a conversão (mapeamento) é uma etapa necessária (Haupt e Haupt, 2004). Alguns problemas podem ocorrer na tentativa de mapear uma representação contínua para binária. Uma das alternativa é alterar a codificação binária tradicional para a codificação de Gray (Jong, 2006; Goldberg, 1989).

\section{Representação Contínua}

Os AGs podem utilizar, diretamente, uma representação contínua. Isso devido aos erros de precisão que podem ocorrer durante a execução do algoritmo. 
Neste modelo de representação a decodificação não é necessária, o que podem simplificar ainda mais a implementação. No entanto, deve-se implementar os operadores do AG de forma adequada, a fim de obter os mesmos benefícios da representação binária.

\subsubsection{Operadores em AGs}

Para que um AG possa encontrar a melhor solução para um problema é necessário realizar uma série de operações sobre os indivíduos da população. A seguir, serão apresentados alguns dos operadores mais utilizados.

\section{Fitness}

A aptidão de um indivíduo em um AG é o valor de uma função objetivo para seu fenótipo. Para o cálculo do fitness para indivíduos de representação binária, deve-se primeiro decodificá-lo para que a função objetivo tenha condição de avaliá-lo.

Determinar a função fitness em problemas de otimização multi-objetivo não é uma tarefa fácil, isso porque, normalmente, os objetivos dessas funções são conflitantes.

\section{População}

A população em um AG representa uma coleção de soluções, as quais são caracterizadas como indivíduos ou cromossomos. Os aspectos mais importantes de uma população são (Sivanandam e Deepa, 2007):

- A geração de um população inicial;

- O tamanho da população.

Estes aspectos exercem grande influência sobre o comportamento de um AG. A inicialização de uma população geralmente é realizada de forma aleatória. Uma boa inicialização deve garantir a diversidade da população na amostra.

Quanto ao tamanho da população, é importante escolher um valor adequado, a fim de explorar apenas uma parte do espaço de busca.

Se a amostragem for ideal, ou seja, se a população foi bem inicialiazada (aleatóriamente) e o tamanho da população não for exagerado, o AG convergirá para o ótimo global com grande eficiência. 


\section{Seleção}

Seleção é o processo onde são escolhidos os indivíduos para reprodução. Quanto maior o fitness do indivíduo, maior a chance de ser selecionado. Um parâmetro de AGs, conhecido como pressão de seleção ( $p s)$, é definido como o grau (taxa) em que os melhores indivíduos serão favorecidos, ou seja, se a pressão de seleção for alta, mais indivíduos serão selecionados (Sivanandam e Deepa, 2007). A taxa de convergência de uma população geralmente está relacionada à pressão de seleção exercida sobre a população.

Há vários métodos para a seleção dos indivíduos da população, entre eles:

- Seleção Proporcional (Roleta): os indivíduos são proporcionalmente agrupados pelo fitness e selecionados aleatóriamente. Consequentemente, os indivíduos com os maiores valores de fitness têm maiores chances de serem escolhidos.

- Seleção por Ranking: dois pares indivíduos são selecionados aleatóriamente. Em cada par é realizado um torneio selecionando os pais da geração. Este é considerado um dos piores métodos de seleção.

- Seleção por Torneio: é realizada uma competição entre $N$ indivíduos da população. O vencedor é escolhido para um conjunto contendo os reprodutores (mating pool). A competição é repetida até que o conjunto esteja completo. A eficiência deste método está relacionada com a pressão de seleção exercida.

\section{Recombinação (Crossover)}

Após a seleção, a população fica repleta de bons indivíduos. A recombinação garante que as melhores características sejam recombinadas para criar uma descendência ainda melhor.

O operador seleciona aleatóriamente um par de indivíduos. Um ponto de corte é selecionado aleatóriamente na cadeia de símbolos do cromossomo (entre os alelos). Então, o blocos de alelos (genes) são trocados entre os cromossomos (indivíduos). A Figura ??

O parâmetro denominado probabilidade de crossover $(p c)$, compreende na frequência em que ocorre os cruzamentos. Se a probalidade de crossover for baixa, significa que os descendentes serão cópias idênticas de seus pais.

São várias as técnicas de cruzamento possíveis, no que se refere a quantidade de pontos de corte: 
- crossover de único ponto;

- crossover de dois pontos;

- crossover de $n$ pontos.

\section{Mutação}

Após a recombinação/crossover corre-se o risco da estagnação da população em relação à evolução do AG. Desta forma, adicionar uma pertubação aleatória ao sistema pode desempenhar um papel importante no desempenho do AG. A mutação consiste na alteração aleatória do valor de uma posição cromossomo (alelo). Há muitas formas diferentes de mutação para os diferentes tipos de representação. Por exemplo, na codificação binária, uma mutação pode ser a simples inversão de um bit da string, técnica conhecida como flipping.

O parâmetro denominado probabilidade de mutação $(\mathrm{pm})$, normalmente está relacionada ao comprimento $l$ da string (cromossomo), sendo representada pela razão 1divl. Se a probabilidade de mutação for baixa, poucos indivíduos serão alterados. A mutação impede o AG de convergir para ótimos locais, porém, se a pm for muito alta, corre-se o risco de se tornar uma busca aleatória. 



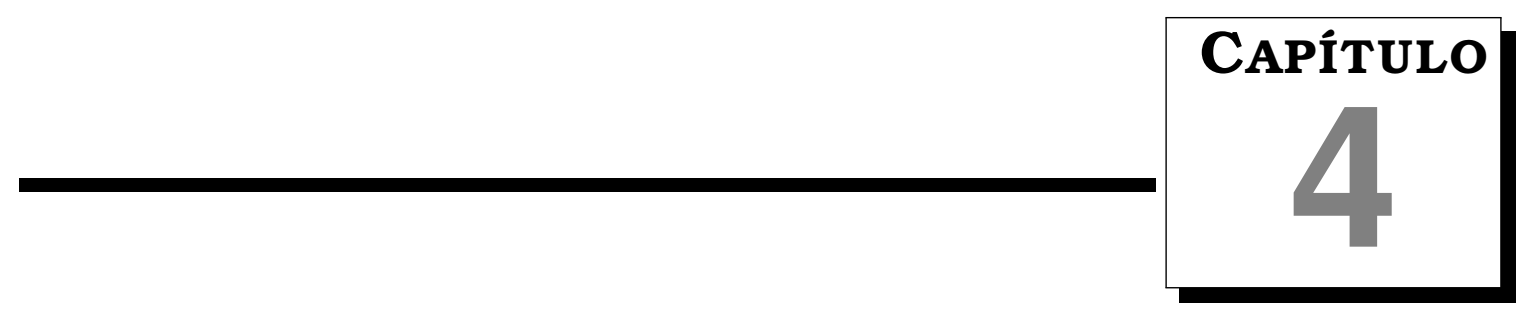

\section{Reutilização de Dados}

\subsection{Contextualização}

Os acessos à memória são conhecidos por serem parcialmente prevísiveis. Durante um determinado período, muitos programas referenciam com maior frequência pequenas regiões do espaço de endereçamento. Esta hipótese sobre o comportamento dos acessos à memória é denominado princípio da localidade dos dados. A hipótese pode ser divida em dois casos:

1. Localidade Temporal: Uma vez que um dado é acessado, este tende a ser acessado novamente durante os próximos ciclos de clock;

2. Localidade Espacial: Um vez que um dado é acessado, dados próximos a este no espaço de endereços tendem a ser acessados durante os próximo ciclos de clock;

Um classe de aplicações, conhecidas como memory-bound ou data-intensive, tais como de processamento multimídia e de processamento de sinais digitais (DSP), precisam acessar uma grande quantidade de dados, normalmente armazenados em memórias off-chip, como SDRAMs ${ }^{1}$. Estas apresentam menor custo e maior capacidade de armazenamento. Entretanto, as memórias off-chip representam um grande gargalo computacional, além de serem as responsáveis por maior parte da energia consumida em sistemas embarcados (Devos et al., $2011 b)$.

\footnotetext{
${ }^{1}$ SDRAM - Synchronous Dynamic Random-Access Memory
} 
A memória cache tem sido o principal dispositivo utilizado na reutilização de dados. Apesar da eficiência das caches, estas memórias não são adequadas para todos os tipos de aplicações. A utilização de memórias scratch-pad $\left(\mathrm{SPM}^{2}\right)$ on-chip tem se mostrado uma abordagem promissora em sistemas embarcados baseados em processador (Catthoor e Danckart, 2002). Esta memórias exploram os principio da localidade.

A fim de reduzir este impacto, têm sido propostos subsistemas de memória aplicando a reutilização de dados em memórias on-chip, tais como cache e Scratch-Pad Memory (SPM).

Algumas técnicas de pré-busca de dados (data prefetch) ajudam a esconder a latência de acesso à memória (Hennessy e Patterson, 2011). Porém, nem sempre é possível empregá-las uma vez que nem todos os programas expõem localidade espacial suficiente.

Para aplicações de tempo real, o emprego de caches é muitas vezes inaceitável, devido principalmente à dificuldade de se obter o tempo de execução no pior caso (WCET ${ }^{3}$ ) (Kandemir et al., 2001).

\subsubsection{Tipos de Reutilização de Dados}

Segundo Catthoor e Danckart (2002), a reutilização de dados é caracterizada quando o acesso de dados durante a execução da aplicação oferecem oportunidades para otimização. A maioria das oportunidades de reutilização de dados ocorrem no interior de loops, pois, é onde ocorrem a maioria dos acessos a memória. A reutilização de dados pode ser classificada de quatro formas (Liu, 2008a):

- Reutilização Auto-Temporal: os mesmos dados são repetidamente acessados por uma única referência à matriz;

- Reutilização Grupo-Temporal: os mesmos dados são acessados por diferentes referências à mesma matriz;

- Reutilização Auto-Espacial: os dados acessados por uma única referência à matriz estão na mesma linha de cache ou no mesmo nivel da hierarquia de memória;

- Reutilização Grupo-Temporal: os dados acessados por diferentes referências estão na mesma linha de cache ou no mesmo nível da hierarquia de memória. Para o caso de reutilização espacial, a organização da memória deve ser considerada.

\footnotetext{
${ }^{2}$ SPM - Scratch-Pad Memory

${ }^{3}$ WCET - Worst Case Execution Time
} 


\subsubsection{Reutilização de Dados em Software}

As abordagens tradicionais para resolução de problemas envolvendo reutilização de dados costumam utilizar caches. Caches são rápidas memórias (SRAM) controladas por hardware (Jacob et al., 2007). Implementam uma heurística (política) para busca e alocação de dados ou instruções. Além disso, o controlador de hardware acrescenta um custo adicional de energia e área (Issenin et al., 2004). Em alguns casos, as caches não resolvem o problema e dados potencialmente úteis podem ser substituídos por outros sem nenhuma utilidade (Liu, 2008b). Além disso, a latência em sistemas que empregam memória cache é imprevisível, impossibilitando sua utilização em sistemas de tempo real (Issenin et al., 2004). Por essas e outras razões, várias arquiteturas tem incorporado memórias on-chip (locais), denominadas memórias scratch-pad.

Memórias scratch-pad, ou simplesmente $\mathrm{SPM}^{4}$, são memórias on-chip controladas por software (Devos et al., 2011b).Seus dados são mapeados em um espaço de endereçamento disjunto da memória off-chip, mas conectada ao mesmo barramento de endereços e dados. A principal diferença entre a scratch-pad e a cache de dados é que a primeira garante o acesso dentro de um único ciclo, enquanto que a segunda está sujeita a uma séria de restrições (Jacob et al., 2007).

Muitos trabalhos envolvendo memórias cache e scratch-pad foram publicados nos últimos anos. Em Panda et al. (2000) foi apresentada uma técnica para explorar memórias on-chip Scratch-Pad em processadores embarcados, com o objetivo de minimizar o tempo de execução de aplicações onde somente a cache de dados não se faz eficiente. Foram mostrados experimentos com núcleos de aplicações conhecidas, como FFT, IDCT, SOR e MatMul (multiplicação de matrizes). Os resultados mostraram significativa melhora no desempenho.

Em Kandemir et al. (2001), foi desenvolvido um framework para a otimização em aplicações para processadores embarcados contendo cache e memória scratch-pad (SPM). O objetivo deste trabalho era melhorar a localidade de dados das aplicações e, consequentemente, aumentar a quantidade de dados reutilizados na SPM. Questões como o partionamento do espaço de memória foram consideradas em seu trabalho. A Figura 4.1 ilustra diferentes alocações de dados on-chip (SPM) , as quais foram consideradas para o algoritmo de multiplicação de matrizes.

Por meio da Figura 4.2 é possivel exemplicar as arquiteturas baseadas em processadores embarcados contendo cache e SPM.

\footnotetext{
${ }^{4}$ Scratch-Pad Memory
} 
(i)

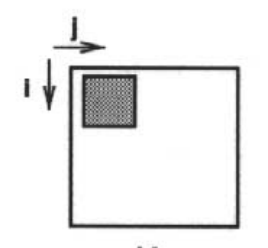

U

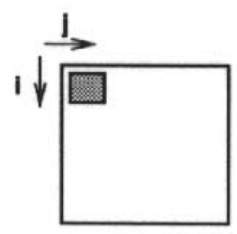

U

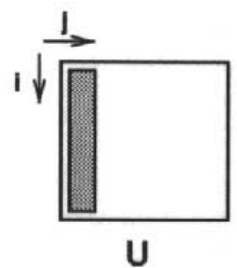

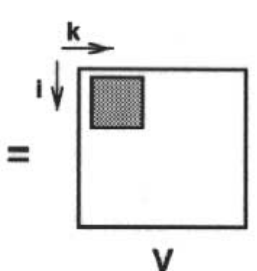

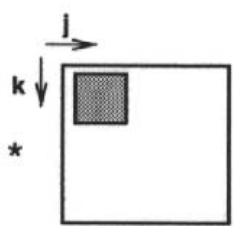

w

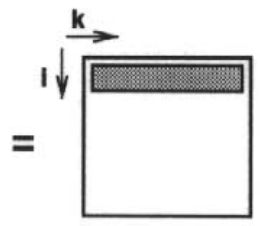

V

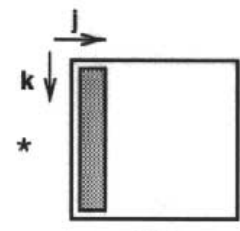

W
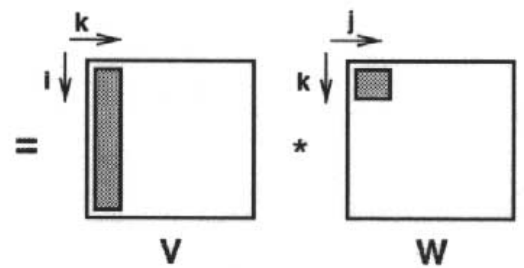

Figura 4.1: Diferentes formas de alocação de dados em SPM para a multiplicação de matrizes (Kandemir et al., 2001)

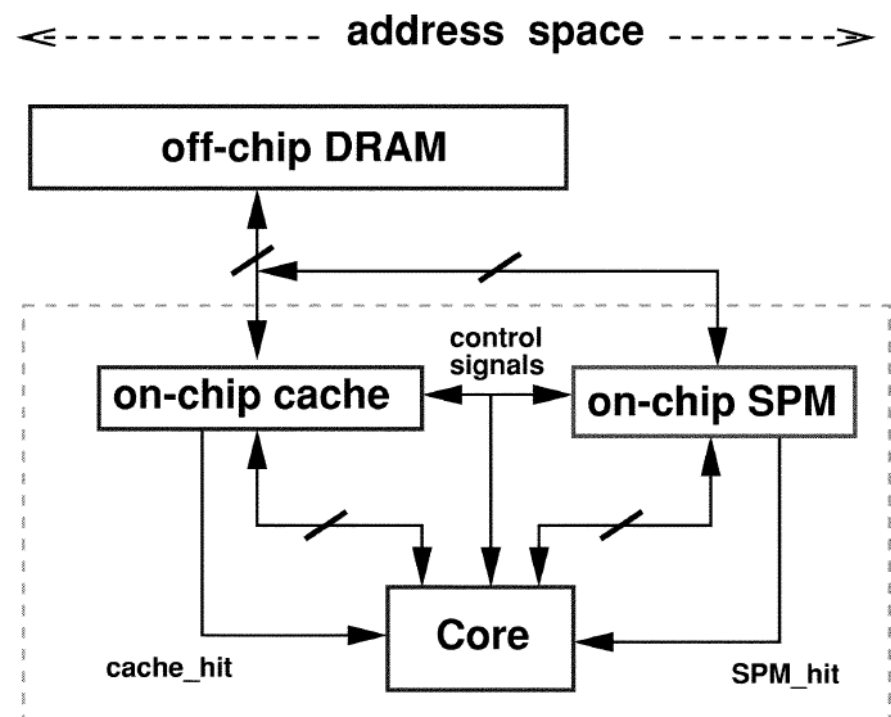

Figura 4.2: Exemplo de arquitetura baseada em processador com cache e SPM (Kandemir et al., 2004b)

\subsubsection{Reutilização de Dados em Hardware}

Em contraste aos processadores de propósito geral (GPPs), em arquiteturas de hardware (FPGA/ASIC) não há uma hierarquia de memória fixa. A hierarquia de memória é customizada de acordo com a aplicação. Além disso, o projetista 
tem total controle sobre as transferências de dados entre as memórias (Devos et al., $2011 b)$.

Segundo Cardoso e Diniz (2008), o desempenho de arquiteturas de hardware pode ser melhorado por meio da reutilização de dados em memórias locais, como blocos de RAM e registradores, por duas razões:

1. a utilização de registradores diminui a latência de acesso aos dados;

2. a reutilização de dados em buffers de armazenamento on-chip reduz o número de acessos a memória externa.

Registradores e blocos de memórias (BRAMs) são as duas formas mais comuns para armazenamentos on-chip em sistemas baseados em FPGAs (Devos et al., 2011b; Kastner et al., 2009). Dependendo da lógica empregada no controle e armazenamento, tanto BRAMs quanto registradores podem ser considerados memórias scratch-pad (SPM). Os registradores costumam ser utilizados para armazenar variáveis escalares, pequenas matrizes e resultados intermediários. Os blocos de memória (BRAM) podem ser utilizadas para armazenar matrizes maiores, como as utilizadas em aplicações memory-bound, revervadas as restrições de área de cada dispositivo (Kastner et al., 2009).

A maioria dos compiladores de hardware tratam de questões que envolvem o mapeamento eficiente de estruturas de software para hardware, visando melhorar a utilização dos recursos computacionais e o desempenho das aplicações. Segundo Liu (2008b), os esforços nesta área se concentram nos seguintes temas:

- Paralelização do código da aplicação e mapeamento em circuitos para explorar os recursos de hardware;

- Escalonamento e sincronização das operações para obter requisitos de temporização;

- Geração de interfaces para componentes hardware e integração de projetos de hardware e software;

- Representação numérica em hardware para explorar os recurso de hardware.

Um exemplo são os compiladores voltados para a exploração do paralelismo, como o compilador LALP (Menotti, 2010). Estas abordagens são capazes de melhorar a utilização de recursos pois reduzem o caminho crítico. Porém, alguns problemas persistem, como os encontrados na paralelização de aplicações que manipulam grande volume de dados. Portanto, para alcançar o desempenho 
desejado, os dados devem ser armazenados nas rápidas memórias on-chip, mas muitas vezes são insuficientes para os dados processados. Desta forma, se faz necessário armazená-los em nas grandes memórias off-chip (Liu, 2008b).

Em Baradaran et al. (2004) foi mostrada uma técnica de reutilização de dados em registradores e blocos de memória RAM on-chip em aplicações baseadas em FPGA. A técnica consistia na análise das opções de reutilização seguida da alocação on-chip de todos os dados para reutilização, não considerando questões referentes a limitação de recursos dos FPGAs.

Em Liu et al. (2006) foi abordado o problema da reutilização de dados no contexto da compilação de hardware, onde foi elaborada uma metodologia sistemática para identificação das opções de reutilização e seleção das opções mais promissoras, considerando também a exploração da técnica em arquiteturas paralelas. A plataforma de desenvolvimento utilizada neste projeto utilizava um dispositivo FPGAs e uma memória externa, explorando a reutilização de dados em memórias on-chip (blocos de RAM) e registradores. Os resultados foram obtidos por meio da implementação em hardware do algoritmo de estimação de movimento de busca completa (FSME), comprovando que a exploração da reutilização de dados on-chip pode reduzir o número de acessos à memória off-chip em até 95\%, além de diminiur o tempo de execução (em alguns casos) em mais de $80 \%$. Entretanto, também foi observado um overhead adicional no consumo de área e energia, que foram introduzidos na exploração da reutilização de dados.

\subsection{Técnicas para Reutilização de Memória}

Reutilização de memória é uma técnica que permite armazenar diferentes conjuntos de dados em uma mesma região de memória, desde que não haja uma intersecção em relação ao tempo de vida dos dados envolvidos na operação. Entende-se por tempo de vida o período entre a produção e o consumo de um dado. Estudando os relacionamentos entre as matrizes referenciadas no código é possível determinar o número de elementos que são produzidos ou consumidos durante cada atribuição. Por meio desta técnica é possível reduzir o tamanho da memória utilizada para armazenar determinados conjuntos de dados (Liu, 2008b).

As técnicas de reutilização de memória normalmente envolvem métodos de mapeamento de endereços.Catthoor e Danckart (2002) propuseram uma técnica para redução do espaço de memória baseada na linearização canônica de uma matriz, seguida por uma operação modular. Por exemplo, para uma ma- 
trix quadrada de tamanho $N$, indexada com $i$ e $j$, foram considerados quatro mapeamentos de endereços:

- $\mathrm{Ni}+\mathrm{j} \bmod \mathrm{b}$,

- $-\mathrm{Ni}+\mathrm{j} \bmod \mathrm{b}$,

- Ni-j $\bmod b$,

- $-\mathrm{Ni}-\mathrm{j} \bmod \mathrm{b}$.

onde $b$ é uma constante inteira.

Pretende-se utilizar neste trabalho o mapeamento de memória apresentado no Ítem 1, porém, sem considerar a operação modular.

Em Darte et al. (2005), foi apresentado um modelo (framework) matemático para estudar o problema da reutilização de memória no contexto da compilação em processadores dedicados. O objetivo deste trabalho foi construir um mapeamento modular, a partir da indexação da matriz original, para uma nova e menor indexação de matriz, que pudesse reutilizar a memória.

\subsection{Trabalhos Relacionados}

O principal meio utilizado para melhorar o desempenho das memórias têm sido transformações de loop, que melhoram a localidade dos acessos aos dados. No entanto, o presente trabalho não aborda este tema e assume que todas as técnicas de transformação de loop para melhorar a localidade já foram realizadas.

Em Panda et al. (1999) foi apresentada uma abordagem que usa uma memória SPM para armazenar variáveis escalares e alguns arrays da aplicação. O particionamento dos dados entre a SPM e a cache é realizado em tempo de compilação e fixo durante a execução de todo o programa. Isto leva à uma utilização inadequada da SPM, uma vez que durante a execução do programa diferentes partes dos arrays e diferentes variáveis podem ser reutilizadas. As abordagens apresentadas por ?) e Verma et al. (2003) apresentam a mesma desvantagem, onde as estruturas de dados mais frequentemente utilizadas são estaticamente alocadas na SPM.

Em Catthoor et al. (1998) foi apresentada uma metodologia para a exploração das transferências de dados (DTSE - Data Transfer and Storage Exploration), que inclui passos de otimização para se alcançar a reutilização de dados. No entanto, nenhum algoritmo foi proposto para automatizar estes passos. 
Técnicas para reutilização de dados têm sido empregadas com sucesso em aplicações específicas desenvolvidas em FPGA. Em Liu et al. (2006) foi apresentada uma técnica para identificação automática das opções de reutilização de dados em memórias on-chip mais promissoras; em Liu et al. (2007) foi apresentado um modelo para o gerenciamento dinâmico dos dados para minimização dos recursos de memória on-chip (SPM).

Em Liu et al. (2007), o problema da reutilização de memória foi considerado no contexto de aplicações em FPGA. Este trabalho utilizou o modelo matemático apresentada anteriormente (Darte et al., 2005) para estender a abordagem da reutilização de dados (Liu et al., 2006). Assim, foi possível resolver os problemas relacionados ao overhead de área. Os resultados deste trabalho mostraram que é possivel obter ótimo desempenho por meio da reutilização de dados, com uma quantidade de recursos aceitável.

Para o gerenciamento dinâmico dos dados foi utilizado um modelo matemático baseado em programação linear e geométrica (Darte et al., 2005). Diferentemente das memórias off-chip (DRAMs), onde os recursos são abundantes e o custo de armazenamento por bit é baixo, os recursos de memória on-chip são limitados e custo de armazenamento é alto. Além disso, o aumento exagerado da quantidade de recursos de memória on-chip pode resultar no aumento do consumo de energia do sistema (Liu et al., 2009a).

Trabalhos mais recentes (Bayliss e Constantinides, 2012; Pouchet et al., 2013), mostram o sucesso da aplicação de técnicas matemáticas, como programação liner e geométrica, na reutilização de dados em SPMs em conjunto com ferramentas de modelagem poliédrica para a descrição matemática dos loops das aplicações, facilitando a geração automática de arquiteturas. 


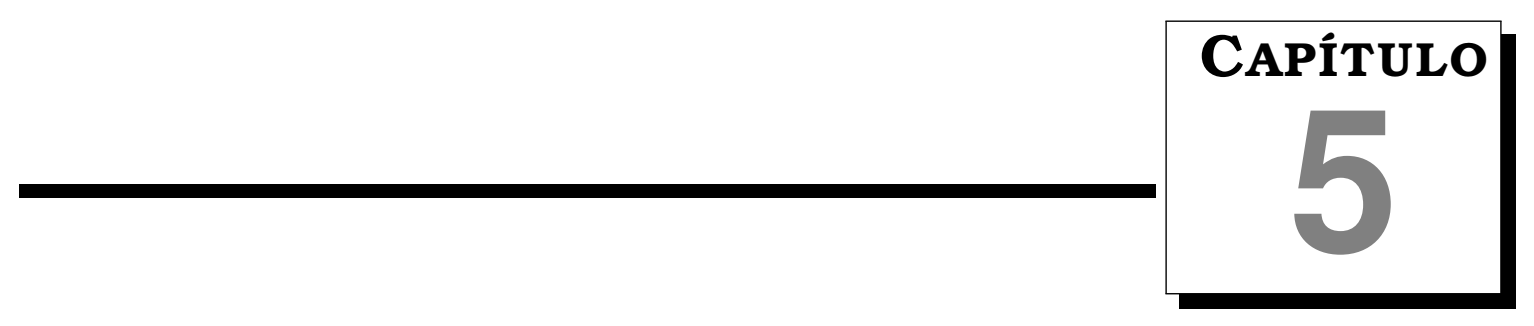

\section{Implementação e Resultados}

Este capítulo detalha a implementação do sistema e discute os resultados obtidos. O trabalho está divido em três etapas, apresentadas nas seções à seguir. A primeira seção descreve o desenvolvimento de um modelo em software que simula o comportamento de uma arquitetura de hardware, esta contendo uma unidade de processamento conectada às memórias off-chip e on-chip. O modelo permite o gerenciamento dos dados entre as memórias, sendo possível avaliar cada configuração de carregamento individualmente. A segunda seção descreve a adaptação do modelo como um problema de otimização e a adaptação em um algorítimo genético (AG) de representação contínua. O objetivo do AG é encontrar a melhores configurações para reutilização de dados, que minimizem o número de acessos à memória off-chip. Também deve-se considerar uma restrição de entrada, o tamanho da memória on-chip (SPM) disponível para a aplicação. A terceira seção descreve a implementação de uma arquitetura de hardware customizada para a reutilização de dados em blocos de memória RAM on-chip. O projeto em hardware foi desenvolvido de forma modular, visando sua futura integração em ferramentas de compilação de hardware. Entre os módulos desenvolvidos se destaca uma arquitetura de hardware específica para aplicações contendo loops aninhados (regulares e irregulares), que facilita a geração de endereços para o acesso às memórias do sistema (SDRAM e BRAM). 


\subsection{Modelagem da Reutilização de Dados}

Visando simplificar a compreesão da abordagem, a Figura 5.1 apresenta um exemplo motivacional, de minemônico EM, que ilustra uma aplicação contendo loops aninhados em torno de variáveis n-dimensionais (arrays). Neste exemplo, considera-se que os dados do array A[ ] são mapeados na memória off-chip e os dados de RA[ ] mapeados na memória on-chip (SPM).

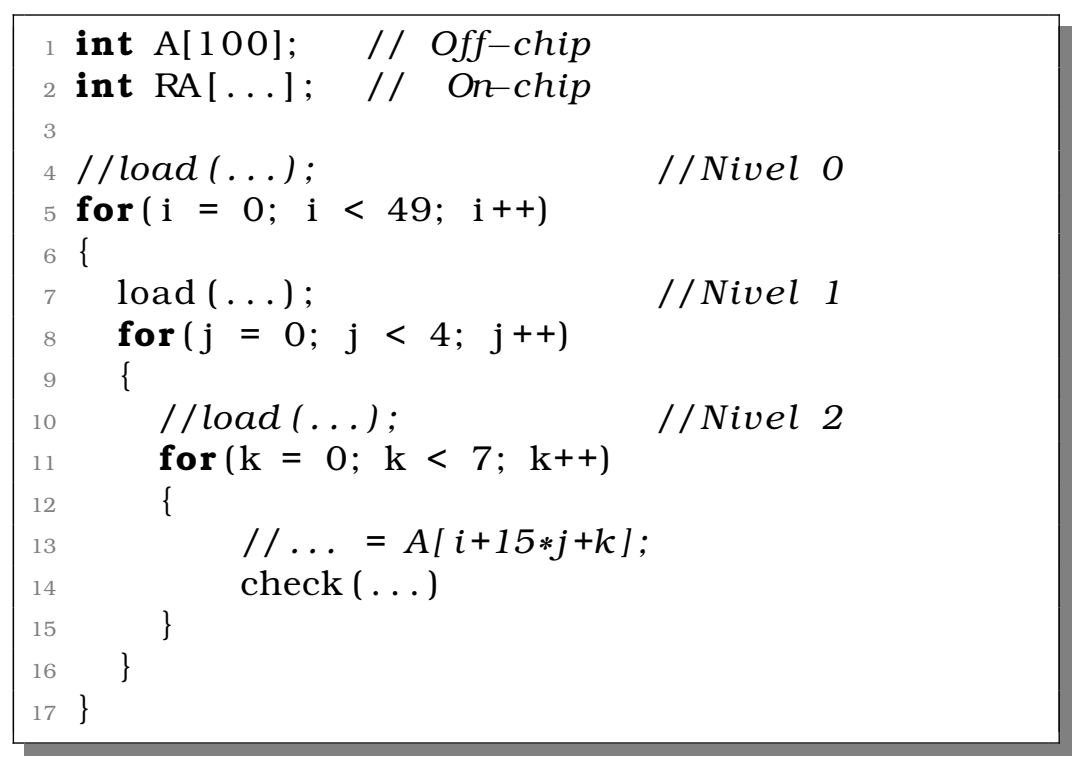

Figura 5.1: O exemplo motivacional (EM) e os locais onde é possivel inserir funções de carregamento. A função de checagem é inserida no nível de loop mais interno.

Entre os níveis dos loops, são inseridas chamadas à uma função para o carregamento de dados, denominada função load(). Diferentemente da cache, na qual o gerenciamento é realizado por um controlador de hardware, inacessível e oculto para o desenvolvedor, em SPMs os carregamentos e armazenamentos são realizados explicitamente. A função load( ) representa um destes carregamentos, inserida entre os niveis dos loops, ilustrando os possiveis locais onde é permitido carregar dados da memória off-chip para a memória on-chip.

A função load( ) tem um comportamento semelhante ao da memória cache, que é carregar um conjunto de dados na memórias on-chip para que sejam reutilizados no futuro. No entanto, as caches tradicionais têm políticas de armazenamento/escrita que são consideradas durante a reutilização de dados. O método descrito neste trabalho não considera a reutilização de dados para operações de escrita. Pode-se considerar que os dados lidos da memória (on-chip/off-chip) são armazenados em variáveis temporárias para o processamento e posterior- 
mente escritos diretamente na memória principal off-chip. Este comportamento se assemelha à política de armazenamento write-through das caches.

O padrão de acesso aos dados em muitas aplicações data-intensive é determinado por alguns coeficientes e índices de loops através de uma função indexação affine (ou linear). A função affine para uma dimensão é apresentada na Equação 5.1 .

$$
f(x)=A \cdot x+b
$$

onde $A$ é um coeficiente, $x$ uma variável e $b$ uma constante qualquer.

A aplicação EM possui três loops perfeitamente aninhados, indexados pelas variáveis $i, j$ e $k$. Há dois arrays, A[ ] e RA[ ], que representam dois conjuntos de dados mapeados nas memórias off-chip e on-chip, respectivamente. Além disto, há três coeficientes implícitos na indexação do array $\mathrm{A}\left[\mathrm{]}\right.$, denominados $C_{i}, C_{j} \mathrm{e}$ $C_{k}$. No caso apresentado, a função de indexação $f$ do array A[ ] é obtida pelo produto dos coeficientes pelos índices correspondentes, como apresentado na Equação 5.2.

$$
\begin{aligned}
& A[f(i, j, k)], \quad c o m \\
& f(i, j, k)=C_{i} \cdot i+C_{j} \cdot j+C_{k} . k
\end{aligned}
$$

Na aplicação exemplificada, os valores dos coeficientes $C_{i}, C_{j}$ e $C_{k}$ são 1,15 e 1 , respectivamente, como mostrado na Figura 5.1 (linha 13). A função de indexação dita o comportamento dos blocos de dados na aplicação, sendo determinante para se traçar um padrão de acesso à memória.

Assim como nas abordagens descritas em Kandemir et al. (2004a) e Liu et al. (2007), o método descrito no presente trabalho não permite o carregamento de dados de um determinado array em mais de um nivel loop, simultaneamente. Desta forma, não são permitidos carregamentos competindo/cooperando entre os níveis para este array. Na aplicação EM, apenas o nível 1 está sem comentários (Figura 5.1 - linha 7), ilustrando uma das possíveis configurações. No entanto, aplicações com vários array podem realizar carregamentos em níveis diferentes, desde que seja selecionado um único nível por array.

A Figura 5.2 (a) ilustra o padrão de acesso aos dados da aplicação EM nas primeiras 28 iterações consecutivas. A configuração de carregamento que corresponde ao padrão de acesso aos dados pode ser determinada pela utilização da três variáveis, Size $X$, Size $Y$ e Gap, ilustradas na Figura 5.2 (b). A primeira variável representa o número de linhas ou blocos (tiles ${ }^{1}$ ), a segunda representa o

\footnotetext{
${ }^{1}$ Tile - bloco contendo dados contíguos.
} 
número de colunas ou elementos contidos em cada bloco, e a terceira representa a lacuna entre as linhas ou blocos.

A função load( ) utiliza as variáveis Size X, Size $Y$ e Gap como parâmetros. As duas primeiras variáveis determinam os limites superiores de um loop aninhado em dois níveis no interior da função, indexados pelas variáveis $x$ e $y$. Portanto, o método emprega carregamentos bidimensionais, o que justifica a representação matricial do array A[ ] utilizada na descrição da abordagem (Figura 5.2).

a )

\begin{tabular}{|c|c|c|c|c|c|c|c|c|c|}
\hline 0 & 1 & 2 & 3 & 4 & 5 & 6 & 7 & 8 & 9 \\
\hline 10 & 11 & 12 & 13 & 14 & 15 & 16 & 17 & 18 & 19 \\
\hline 20 & 21 & 22 & 23 & 24 & 25 & 26 & 27 & 28 & 29 \\
\hline 30 & 31 & 32 & 33 & 34 & 35 & 36 & 37 & 38 & 39 \\
\hline 40 & 41 & 42 & 43 & 44 & 45 & 46 & 47 & 48 & 49 \\
\hline 50 & 51 & 52 & 53 & 54 & 55 & 56 & 57 & 58 & 59 \\
\hline 60 & 61 & 62 & 63 & 64 & 65 & 66 & 67 & 68 & 69 \\
\hline 70 & 71 & 72 & 73 & 74 & 75 & 76 & 77 & 78 & 79 \\
\hline 80 & 81 & 82 & 83 & 84 & 85 & 86 & 87 & 88 & 89 \\
\hline 90 & 91 & 92 & 93 & 94 & 95 & 96 & 97 & 98 & 99 \\
\hline
\end{tabular}

Size Y

Size X $\left\{\begin{array}{c|c|c|c|c|c|c|c|c|c|c|c|c|c|c|}\hline 0 & 1 & 2 & 3 & 4 & 5 & 6 & 7 & 8 & 9 & 10 & 11 & 12 & 13 & 14 \\ \hline 15 & 16 & 17 & 18 & 19 & 20 & 21 & 22 & 23 & 24 & 25 & 26 & 27 & 28 & 29 \\ \hline 30 & 31 & 32 & 33 & 34 & 35 & 36 & 37 & 38 & 39 & 40 & 41 & 42 & 43 & 44 \\ \hline 45 & 46 & 47 & 48 & 49 & 50 & 51 & 52 & 53 & 54 & 55 & 56 & 57 & 58 & 59 \\ \hline 60 & 61 & 62 & 63 & 64 & 65 & 66 & 67 & 68 & 69 & 70 & 71 & 72 & 73 & 74 \\ \hline 75 & 76 & 77 & 78 & 79 & 80 & 81 & 82 & 83 & 84 & 85 & 86 & 87 & 88 & 89 \\ \hline 90 & 91 & 92 & 93 & 94 & 95 & 96 & 97 & 98 & 99 & & & & \\ \hline\end{array}\right.$

Figura 5.2: O carregamento e alinhamento dos endereços para a checagem na aplicação EM. Em a), a memória off-chip é representada como uma matriz e cada número representa um endereço. Os elementos em destaque representam os dados carregados na memória on-chip correspondendo ao padrão de dados da aplicação para a primeira iteração do loop mais externo. A parte b) destaca os endereços da memória off-chip alinhados.

Para a alocação ótima de dados, uma chamada à função load( ) deve realizar o carregamento de todos os dados úteis durante a execução da aplicação.

No exemplo apresentado, no qual a chamada à função está inserida no nível 1, os parâmetros ideais da função são: Size $X=4$, Size $Y=7$ e Gap $=8$. Esta configuração é considerada ótima para o nível 1, pois leva a 100\% de acertos. Ou seja, todos os dados acessados a cada 28 iterações consecutivas são previamente carregados no array RA[ ] antes da execução do nível de acesso principal com o array A[ ] (Figura 5.1 - linhas 13). Uma vez que todos os dados úteis para 
a aplicação estão armazenados no array RA[ ] (on-chip), não há necessidade de acessá-los no array A[ ] (off-chip).

Os carregamentos realizados pela função load( ) respeitam a ordem de execução dos loops. Dependendo do nível que esteja inserida, cada chamada à função resulta na substituição de todo conjunto de dados previamente carregados por outro conjunto de mesmo tamanho (Size $X \times$ Size $Y$ ). Logo, configurações de carregamento inadequadas podem facilmente levar à degradação do desempenho do sistema. Desta forma, é essencial que os parâmetros da função load( ) sejam configurados adequadamente, assim como escolhido o nível de loop em que esta deve ser inserida.

A Figura 5.4 apresenta o código da função load( ), em que há outras duas variáveis, denominadas Dist e Base. A primeira representa a distância entre os primeiros elementos de cada bloco (tile). A segunda representa o primeiro endereço acessado em cada carregamento. As variáveis Dist e Base são de grande importância para a função check( ), detalhada a seguir.

O valor da variável Dist é obtido pela soma das variáveis Size y e Gap. O valor da variável Base depende do nível (entre os loops) em que a função load( ) está inserida na aplicação, pois a esta é atribuída a mesma função de endereçamento do array principal (Equação 5.2).

Para exemplificar o cálculo das variáveis Dist e Base, supondo que a função load( ) está ativa no nível 1, uma possível configuração para o carregamento de dados seria uma chamada à função com os seguintes parâmetros: load $(i, 0,0,4,7,8)$, onde $i$ é o índice do loop mais externo e os índices $j$ e $k$ são ignorados $^{2}$. As variáveis Size $X$, Size $Y$ e Gap são passadas como parâmetros da função com os valores 4,7 e 8, respectivamente. Neste contexto, como o cálculo da variável Dist não depende nível em que a função load( ) está inserida: Dist $=$ Size $Y+$ Gap $=15$. No entanto, como o cálculo da variável Base depende dos nível de loop em que a função está inserida, seu valor passa a representar apenas uma parte da função de endereçamento principal : Base $=f(i)=C_{i} . i$.

A função check ( ), apresentada na Figura 5.1 (linha 14), é responsável por verificar se um determinado dado está ou não armazenado na memória on-chip. A verificação é particularmente útil quando a configuração dos parâmetros da função load( ) não correspondem à alocação ótima de dados, possibilitando a avaliação de cada configuração de carregamento individualmente. Além disso, no interior da função check( ) é realizado o mapeamento de endereços, como mostrado na Figura 5.4 (linhas 7, 8 e 13 ).

\footnotetext{
${ }^{2}$ No caso exemplificado, o motivo pelo qual os índices $j$ e $k$ são ignorados é reflexo da posição dos loops correspondentes. Como estão situados logo abaixo da chamada da função load ( ) seus valores permanecem nulos pelo próprio fluxo de execução dos loops
} 


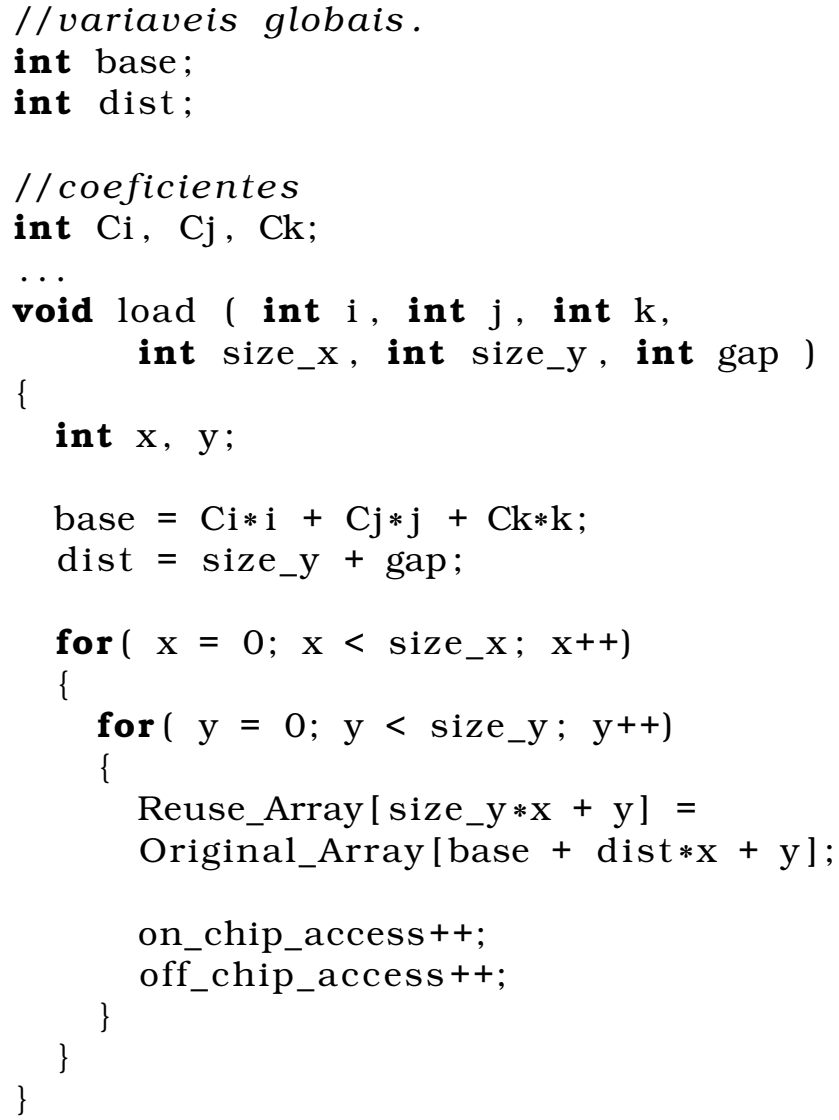

Figura 5.3: A função load( ), na qual são realizados os carregamentos de dados.

A simplicidade computacional da verificação e o correto mapeamento de endereços, realizados pela função check( ), dependem do alinhamento dos endereços no array principal. As variáveis Dist e Base, calculadas no interior da função load( ), tornam possível tal alinhamento, gerando um padrão de acesso retangular ( Figura 5.2(b)).

Entretanto, considerando casos em que os carregamentos sejam realizados em qualquer um dos níveis de loop, como excessão do nível mais externo (nível 0), os dados tendem a se deslocarem durante a execução da aplicação. Este padrão é conhecido como sliding window (Fingeroff, 2010). Um problema ocorre quando a "janela" ultrapassa os limites da matriz e parte dos dados verificados passam a residir nas primeiras e últimas colunas da matriz, dificultando a verificação e o mapeamento de endereços. Este problema foi solucionado com a fixação da variável Base na primeira coluna, permitindo o deslocamento da matriz ao invés da "janela" de dados, como ilustrado na Figura 5.5). Tal efeito foi obtido pela subtração do endereço verificado pela variável Base, como mostra a Figura 5.4 (linhas 7 e 8 ). 


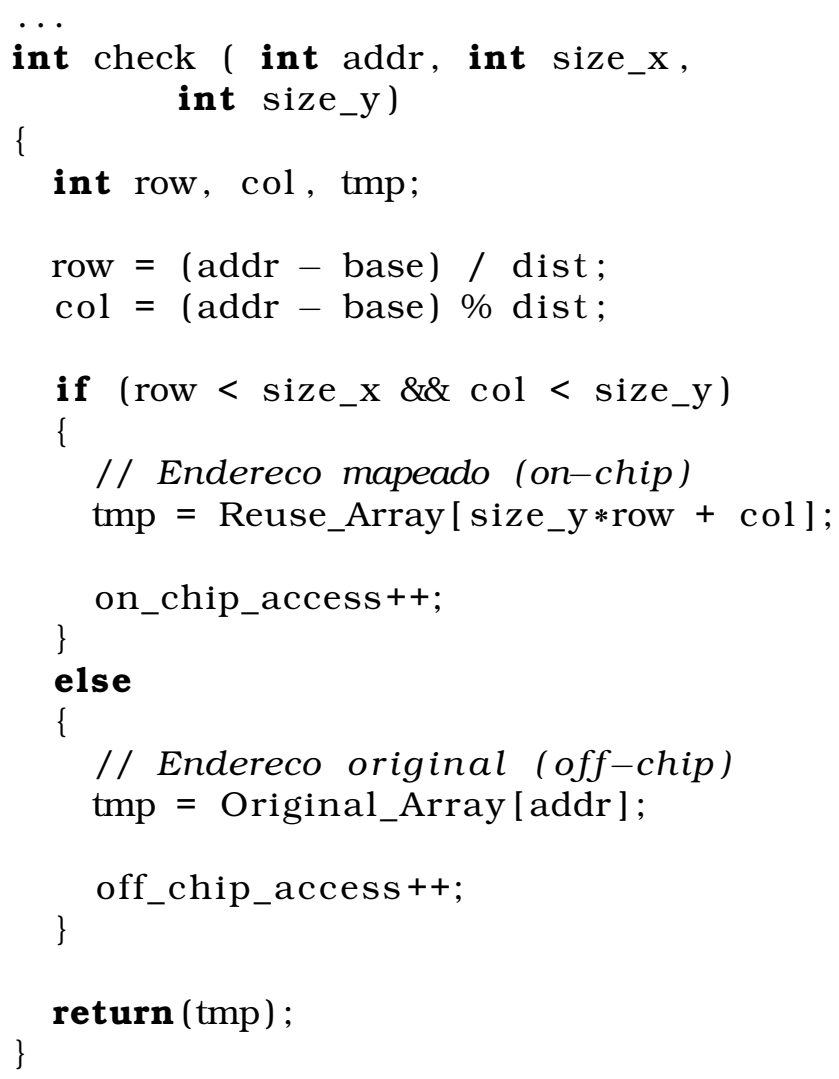

Figura 5.4: A função check( ), na qual são realizadas a verificação e o mapeamento de endereços off-chip/on-chip.

Assim, considerando que Size $X$ e Size $Y$ definem o tamanho da memória on-chip, um determinado dado (off-chip) estará armazenado na memória on-chip desde que satisfeita a seguinte condição:

$$
\text { row }<\text { Size } X \wedge \text { column }<\text { Size } Y
$$

onde row e column são as novas linhas e colunas que compõem o endereço off-chip após o alinhamento, como mostrado na Figura 5.4 (linha 10).

É importante destacar que as operações realizadas no interior das funções load( ) e check( ) não interferem na ordem de execução dos loops ou acesso aos dados da aplicação. O alinhamento de endereços pode ser considerado como uma reorganização virtual da matriz da aplicação, uma vez que as variáveis envolvidas no processo (Dist e Base) atuam somente no interior das funções.

Quando realizado um carregamento, cada dado armazenado na memória onchip possui um correspondente na memória off-chip. Assim como em Liu et al. (2007), a função load( ) implementa os carregamentos de forma que os dados sejam alocados em endereços sequenciais na memória on-chip, ou seja, sem espaços entre os blocos. Desta forma, é possivel realizar a reutilização de dados 
a)

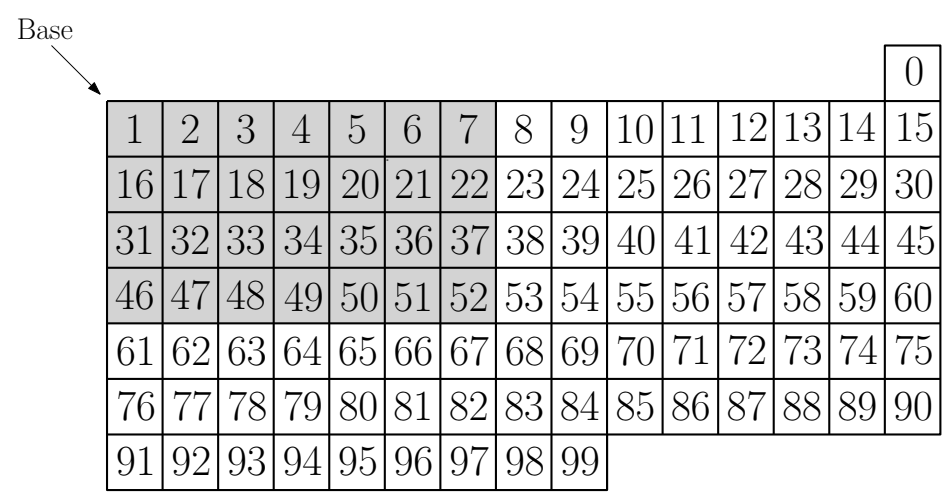

\begin{tabular}{|c|c|c|c|c|c|c|c|c|c|c|c|c|c|}
\hline \\
\hline & & & & & & & & & & & & 0 & 1 \\
\hline 2 & 3 & 4 & 5 & 6 & 7 & 8 & 9 & 10 & 111 & \begin{tabular}{l|l}
12 & 13 \\
\end{tabular} & 14 & 15 & 16 \\
\hline 17 & 18 & 19 & 20 & 21 & 22 & 23 & 24 & 25 & \begin{tabular}{l|l}
26 & 2 \\
\end{tabular} & \begin{tabular}{l|l}
27 & 28 \\
\end{tabular} & 29 & 30 & 31 \\
\hline 32 & 33 & 34 & 35 & 36 & 37 & 38 & 39 & 40 & \begin{tabular}{l|l}
41 & 4 \\
\end{tabular} & \begin{tabular}{l|l}
42 & 43 \\
\end{tabular} & 34 & 45 & 46 \\
\hline 47 & 48 & 49 & 50 & 51 & 52 & 53 & 54 & 55 & \begin{tabular}{l|l}
56 & 5 \\
\end{tabular} & \begin{tabular}{l|l}
57 & 58 \\
\end{tabular} & 59 & 60 & 61 \\
\hline 62 & 63 & 64 & 65 & 66 & 67 & 68 & 69 & 70 & \begin{tabular}{l|l}
71 & 7 \\
\end{tabular} & \begin{tabular}{l|l}
72 & 73 \\
\end{tabular} & 74 & 75 & 76 \\
\hline 77 & 78 & 79 & 80 & 81 & 82 & 83 & 84 & 85 & \begin{tabular}{l|l}
86 & 8
\end{tabular} & \begin{tabular}{l|l}
87 & 88 \\
\end{tabular} & 89 & 90 & 91 \\
\hline 92 & 93 & 94 & 95 & 96 & 97 & 98 & 99 & & & & & & \\
\hline
\end{tabular}

Figura 5.5: O movimento dos dados em duas iterações do loop mais externo da aplicação EM. A parte a) representa a segunda iteração do loop externo. A parte b) representa a terceira iteração do loop, mostrando que a coluna na variável Base permanece fixa na primeira coluna.

consumindo poucos recursos da memória on-chip. Por outro lado, esta característica leva à problemas referentes ao mapeamento de endereços.

É importante garantir que os dados acessados on-chip correspondam às cópias contidas na memória off-chip. Para se manter a consistência dos dados acessados, deve-se realizar o correto mapeamento de endereços entre as memórias.

O mapeamento de endereços desenvolvido no presente trabalho é baseado em duas técnica descritas na literatura: Kandemir et al. (2004a) (mapeamento direto) e Liu et al. (2007) (mapeamento modular). No entanto, como o resultado depende das operações de divisão (/) e módulo (\%), mostradas na Figura 5.4 (linhas 7 e 8), o mesmo também pode ser classificado com mapeamento modular.

Nos trabalhos de Kandemir et al. (2004a) e Absar e Catthoor (2005) são utilizados modelos de custos que atribuem valores às transfências de dados entre as memórias off-chip e SPM. O presente trabalho também faz uso de um modelo de custos, tornando possível a avaliação de diferentes configurações de carregamento. 
Como pode ser observado nas Figuras 5.3 e 5.4, há duas variáveis que realizam a contagem do número de acessos às memória off-chip e on-chip, denominadas off_chip_access e on_chip_access, respectivamente.

O modelo de custos visa simular o comportamento de uma arquitetura de hardware, esta contendo uma unidade de processamento conectada às memórias off-chip e on-chip. Adicionalmente, é possível atribuir um peso às variáveis off_chip_access e on_chip_access, caracterizando a latência de acesso às memórias do sistema. Como é difícil estimar com precisão o tempo de acesso à memórias off-chip, como DRAMs, optou-se por um modelo simplificado. A Equação 5.3 descreve este modelo.

$$
\text { Cycles }=L_{o f f} \cdot A c c_{o f f}+L_{o n} \cdot A c c_{o n}
$$

onde $L_{o f f}$ e $L_{o n}$ são as latências de acesso às memórias off-chip e on-chip, e $A c c_{o n}$ e $A c c_{o f f}$ são os valores obtidos pelas variáveis off_chip_access e on_chip_access, respectivamente.

Os valores que representam as latências de acesso (off-chip/on-chip) podem ser escolhidos arbitrariamente. Por exemplo, se escolhidos os valores: $L_{o f f}=$ 10 e $L_{o n}=1$. Isto significa que se um dado está armazenado na memória offchip (DRAM) o tempo de acesso é igual a 10 ciclos de clock, se armazenado na memória on-chip (SPM) o tempo é igual a 1 ciclo de clock. Neste trabalho, optouse por avaliar somente o número de acessos à memória off-chip, ao invés do tempo de acesso. Logo, foram utilizados os seguintes valores: $L_{o f f}=1$ e $L_{o n}=0$.

O problema de otimização abordado no presente trabalho consiste na minimização do número de acessos à memória off-chip, assim como o tamanho da memória on-chip necessária para a reutilização de dados on-chip. O sistema deve ser capaz de encontrar automaticamente a melhor configuração para os carregamentos, decidindo o local/nível onde a função load( ) deve ser inserida no código da aplicação e quais os dados que devem ser armazenados no buffer on-chip. Como apresentado na seção, tais requisitos podem ser obtidos através da configuração ideal dos parâmetros do modelo (Size X, Size Y e Gap). 


\subsection{Implementação do Algoritmo Genético e Resultados}

O Algoritmo Genético (AG) implementado neste trabalho tem como objetivo minimizar o número de acessos à memória off-chip. Para tal, foi desenvolvida uma codificação específica para representar o modelo, este descrito na seção anterior.

Segundo Jong (2006), as principais características que definem a eficácia de um AG na resolução de um problema são: a representação do indivíduo, a função objetivo e o correto ajuste dos parâmetros. A Figura 5.6 ilustra a representação utilizada neste trabalho, a qual descreve os indivíduos da população.

a)

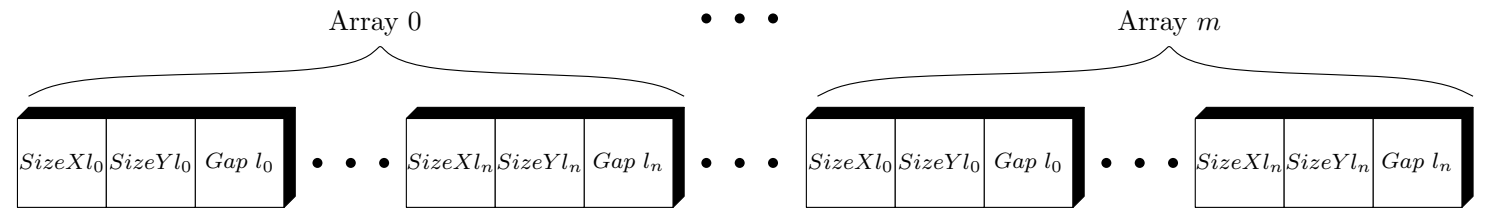

$\mathrm{A}[]$

b)

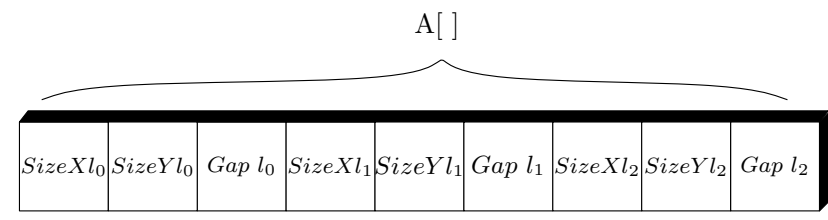

Figura 5.6: Representação do cromossomo para o AG. A parte (a) ilustra uma representação genérica de um indivíduo e a parte (b) apresenta um indivíduo para a aplicação EM, mostrada na Figura 5.1.

A unidade mais básica de um cromossomo é o alelo. De acordo com a Figura 5.6 (a), os três primeiros alelos consecutivos representam as variáveis Size $X$, Size Y e Gap para o nivel 0; os próximos três alelos consecutivos representam as mesmas variáveis para o nivel 1; e assim por diante até o nível $n$, onde $n$ é o número de loops aninhados presentes na aplicação. Adicionalmente, cada array apresenta seu próprio cromossomo, partindo do array 0 até o arrary $m$, onde $m$ é o número total de arrays. O intervalo de variação de cada alelo depende do tamanho do array corresponde. Logo, o tamanho do espaço de busca cresce exponencialmente em função do número de loops, do número arrays e do tamanho dos arrays da aplicação.

A Figura 5.6 (b) mostra ilustra seria um cromossomo para a aplicação EM apresentada na Figura 5.1. Como o exemplo apresenta três loops aninhados, há nove variáveis/alelos, sendo estas Size $X$, Size Y e Gap, para cada um dos três níveis. Já o intervalo de variação de cada um das variáveis é $[0,100]$. É importante destacar que, se mais arrays fossem utilizados na aplicação EM, seriam nove variáveis para cada array. 
Como pode ser observado, o espaço de busca da aplicação EM é pequeno. No entanto, para os benchmarks utilizados neste trabalho o espaço de busca é consideravelmente grande, principalmente em razão do tamanho dos arrays utilizados.

Como as variáveis do problema são discretas, optou-se por implementar um AG de representação contínua. A implementação é baseada na versão SGA (Simple Genetic Algorithm), disponibilizada on-line pelo laboratório KanGAL ${ }^{3}$ (Indian Institute of Technology Kanpur). As principais características do AG são:

- Crossover SBX (Simulated Binary Crossover)

- Mutação polinomial;

- Seleção por torneio;

- Manipulação das restrições na seleção.

Os operadores para crossover e mutação apresentam alguns parâmetros específicos, sendo estes:

- Índice de distribuição para crossover: $\eta_{c}$ (SBX) (Deb e Agrawal, 1994);

- Índice de distribuição para mutação: $\eta_{m}$ (mutação polinomial) (Deb e Agrawal, 1999);

- Parâmetro de restrição da seleção: $\Sigma$ (Manipulação das restrições)

\subsubsection{Resultados}

Visando demonstrar a efetividade do método proposto para a minimização dos acessos à memória off-chip, foram selecionados quatro benchmarks que representam típicas aplicações data-intensives: Sobel, FSME (Full Search Motion Estimation), QSDPCM (Quad-Tree Structured Difference Pulse Code Modulation) e MM (Multiplicação de Matrizes). A Tabela 5.1 apresenta suas principais características:

Os benchmarks Sobel, FSME e MM64 tem loops acessos regulares no interior dos loops, enquanto que QSDPCM se diferencia dos demais, tendo acessos irregulares na função de indexação da matriz. O núcleo deste benchmark é apresentado na Figura 5.7.

A Figura 5.8 apresenta o comportamento do AG para o benchmark Sobel, que converge para uma solução ótima usando os parâmetros previamente configurados, estes mostrados na Tabela 5.2.

\footnotetext{
${ }^{3}$ http://www.iitk.ac.in/kangal/codes.shtml
} 
Tabela 5.1: Benchmarks utilizados para validação do método proposto.

\begin{tabular}{lccc}
\hline Benchmark & Tamanho & Unidade & Loops aninhados \\
\hline Sobel & $144 \times 176$ & pixels & 4 \\
FSME & $144 \times 176$ & pixels & 6 \\
QSDPCM & $144 \times 176$ & pixels & 4 \\
MM & $64 \times 64$ & elementos & 3 \\
\hline
\end{tabular}

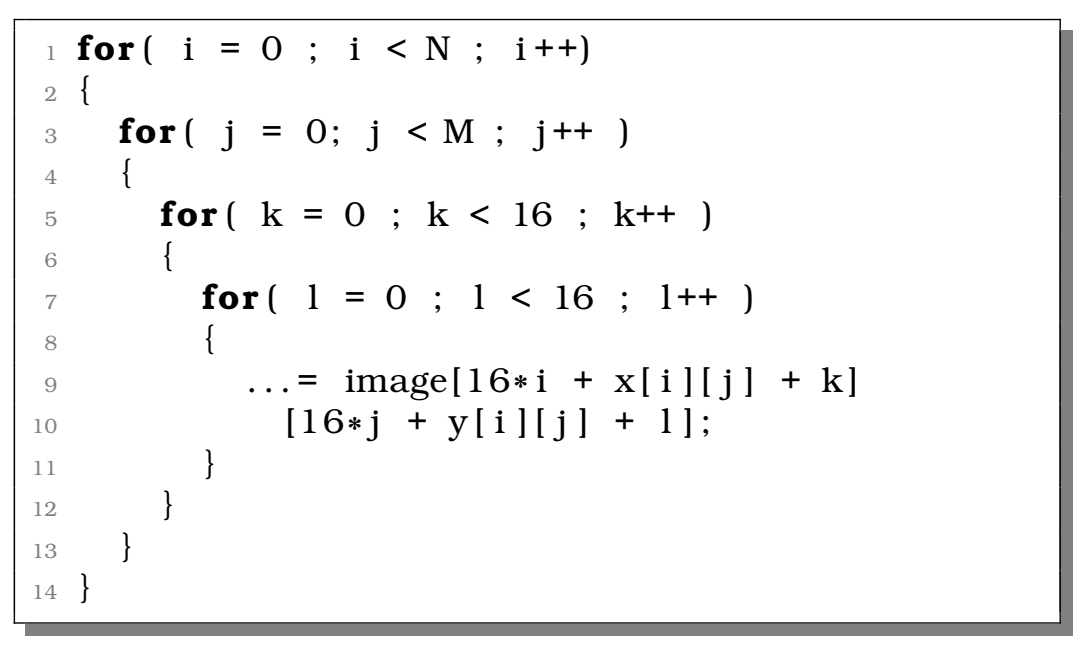

Figura 5.7: Núcleo do benchmark QSDPCM.

Tabela 5.2: Parâmetros de configuração do Algoritmo Genético para o benchmark Sobel.

\begin{tabular}{|c|c|}
\hline Número de gerações & 700 \\
\hline Tamanho da população & 240 \\
\hline Param. restr. seleção & 0.3 \\
\hline Tamanho do torneio & 2 \\
\hline Probabilidade de crossover & 0.95 \\
\hline Probabilidade de mutação & 0.05 \\
\hline Ind. distr. cross. $\left(\eta_{c}\right)$ & 2 \\
\hline Ind. distr. mut. $\left(\eta_{c}\right)$ & 20 \\
\hline Restrição de memória & 535 \\
\hline
\end{tabular}

Baseado nos parâmetros apresentados, foi escolhida uma população de 200 indivíduos, onde cada um representa um possível padrão de acesso à memória. Assim, para cada geração do AG, operadores são aplicados sobre estes indivíduos, gerando novas configurações. A Figura 5.8 mostra o fitness do melhores e dos piores individuos para cada geração, além do fitness médio, mostrando graficamente a evolução da população. A fitness é métrica que representa a qualidade das soluções para padrões de acesso à memória que minimizam os acessos à memória off-chip. Como mostrado na Figura 5.8, o ponto de convergência se encontra próximo ao número de 500 gerações. 


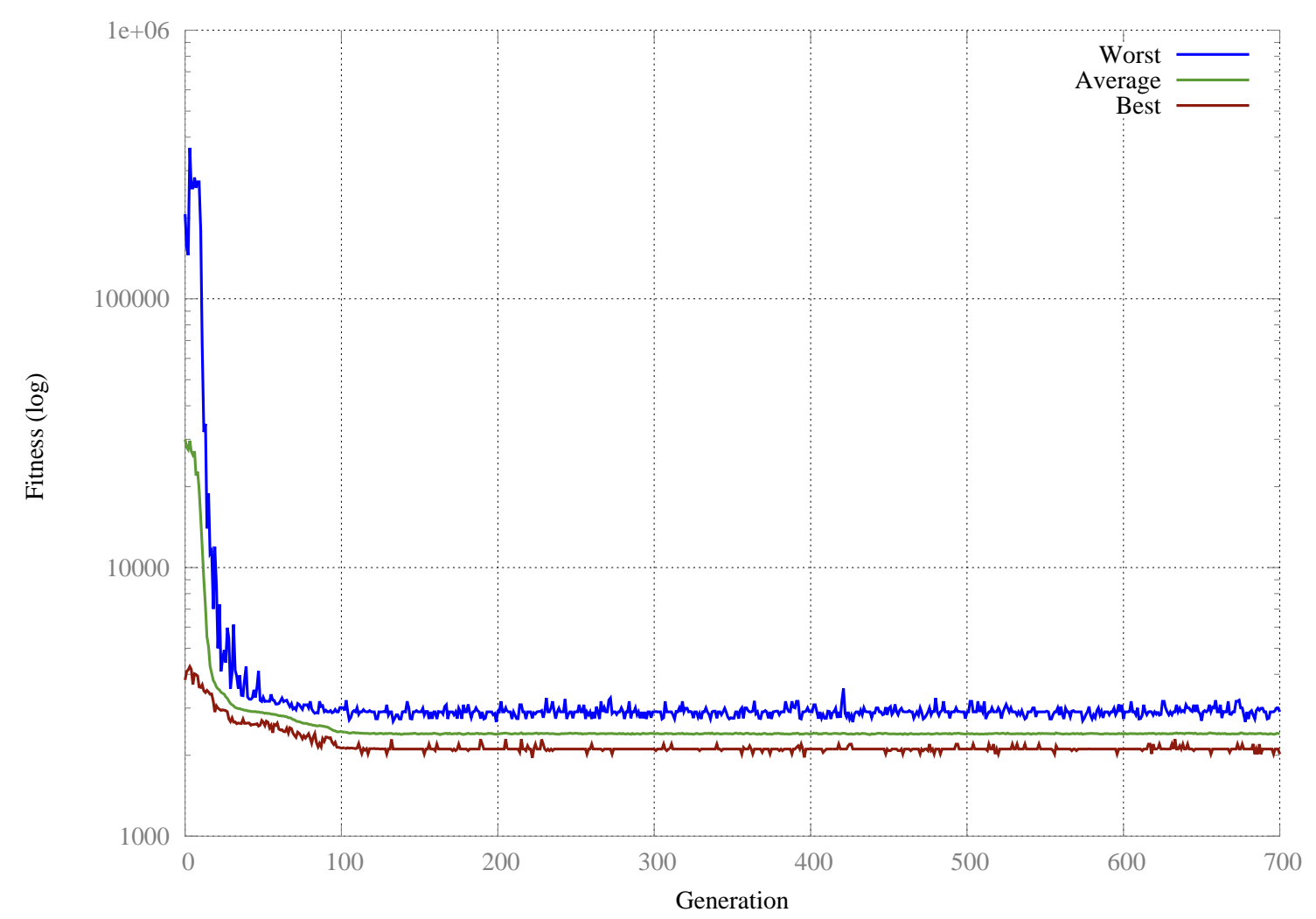

Figura 5.8: Convergência do Algoritmo Genético para a aplicação Sobel.

O mesmo processo é utilizado para encontrar o ponto de convergência foi aplicado à outros casos de uso. A Figuras 5.9 e 5.10 demonstram a redução do número de acessos off-chip para todos os quatros benchmarks avaliados. Estas figuras incluem três informações para cada benchmark, que são: Sem reutilização de dados, Ótimo local e Ótimo global. A primeira informação mostra o número de acessos da aplicação somente acessando dados da memória off-chip, a segunda indica o número de acessos para uma memória on-chip de tamanho limitado que é menor que o necessário para armazenar todos os dados necessários para computação no interior de cada loop. A última informação é o númeor de acessos considerando uma memória on-chip capaz de armazenar todos os dados. Este último caso representa o ótimo global encontrado pelo Algoritmo Genético, o qual define esta capacidade automaticamente quando nenhuma restrição for previamente imposta pelo usuário na exploração do espaço de busca.

Para o benchmark Sobel foi obtido $94.42 \%$ de ganho para a solução ótima global e 83.3\% para a solução ótima local em número de acessos usando somente 540 bytes de recursos de memória on-chip. Para a solução ótima local o Algoritmo 


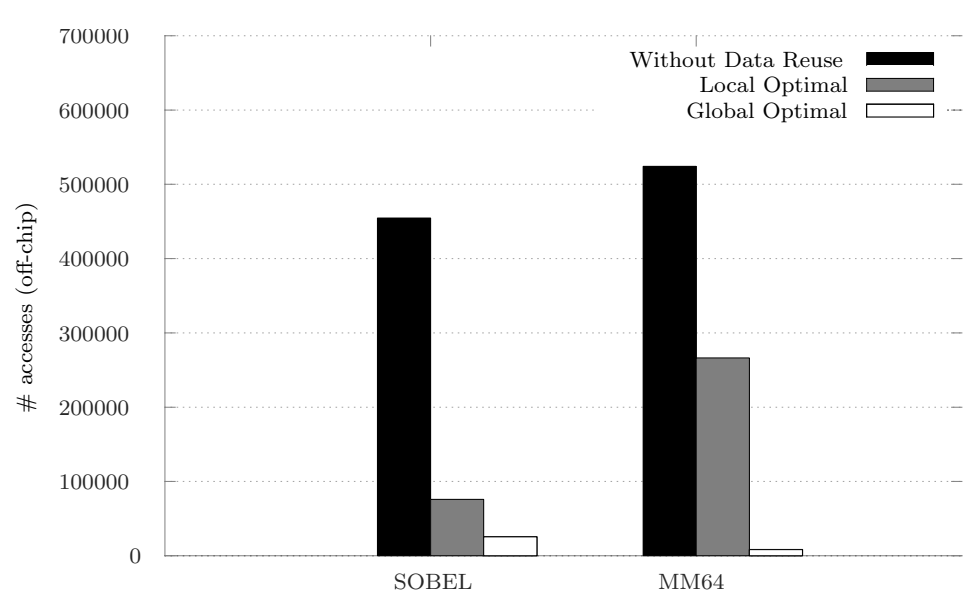

Figura 5.9: O número de acessos à memória off-chip para os benchmarks Sobel e MM64 mostrando uma solução sem reutilização de dados, e outras duas com reutilização de dados, uma para o ótimo local e outra para o ótimo global.

Genético indica que é necessário um tamanho de memória on-chip de 25KB. Para a solução ótima local há uma restrição de entrada para o AG, onde tamanho da memória on-chip foi limitado à $1 \mathrm{~KB}$. Este número foi escolhido arbitrariamente e pode representa um dispositivo de hardware real com limitação na capacidade de recursos on-chip.

A principal vantagem deste trabalho é a flexibilidade da abordagem, pois permite a definição de um tamanho de memória on-chip como restrição. Ainda assim, o AG é capaz de encontrar a melhor solução. As soluções tradicionais, tal como em Liu et al. (2007), não permitem a entrada de restrições de tamanho de memória e geram um conjunto de projetos baseados no volume de dados à serem processados, tal como o frame de uma imagem.

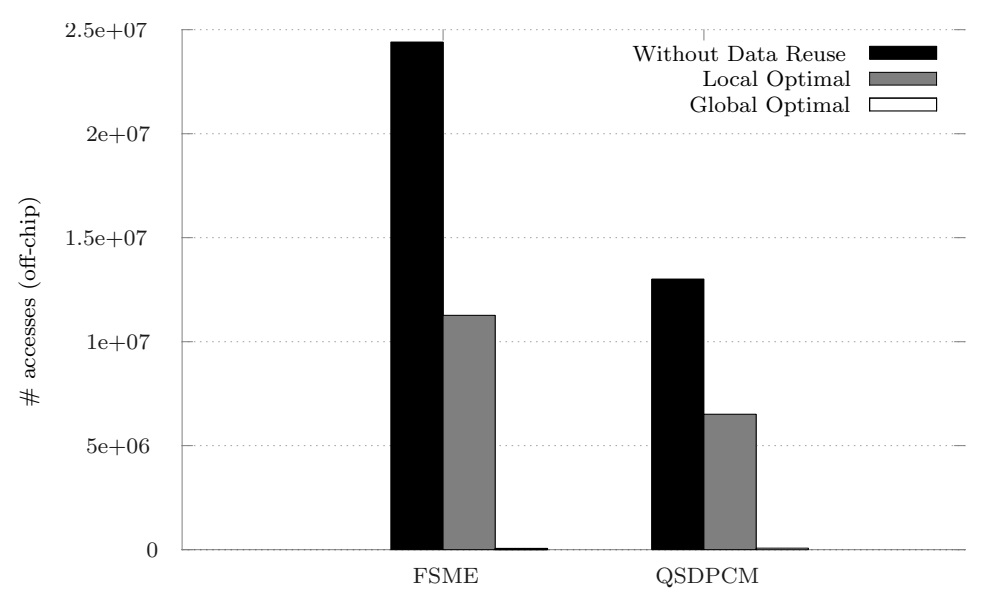

Figura 5.10: O número de acessos à memória off-chip para os benchmarks FSME e QSDPCM mostrando uma solução sem reutilização de dados, e outras duas com reutilização de dados, uma para o ótimo local e outra para o ótimo global. Para a solução ótima global as colunas são muito pequenas, uma vez que o ganho obtido é extremamente grande em relação à solução ótima local. 
Ambos benchmarks, MM64 e FSME usam um padrão de acesso regular às matrizes, tal como o Sobel. Como mostrado nas Figuras 5.9 e 5.10, também é possível obter uma redução significativa dos acessos à memória externa.

O benchmark FSME apresenta é o mais complicado no que se refere ao número de loops aninhados, apresentando seis loops e dois arrays, necessitando de um cromossomos de 36 alelos para representar um indíviduo do AG. Apesar do grande número de configurações possiveis, o AG é capaz de identificar a solução ótima global e soluções ótimas locais.

Para o benchmark QSDPCM, o qual apresenta acessos irregulares aos arrays, os resultados são mostrados na Figura 5.10. Inserindo como entrada do AG uma restrição de memória de $1.5 \mathrm{~KB}$, o ganho obtido foi de $49.9 \%$. Para o caso ideal (ótimo global), no qual não há qualquer restrição de armazenamento on-chip, o ganho obtido foi de $98.4 \%$.

\subsection{Projeto da Arquitetura de Hardware}

A técnica proposta neste trabalho gera como saída um conjunto de parâmetros indicando qual é o padrão de acesso à memória da aplicação. Esta informação pode ajudar um projetista a definir uma arquitetura de hardware visando reduzir os acessos à memória off-chip para uma determinada capacidade de memória on-chip.

A arquitetura de hardware foi projetada em módulos para facilitar a integração do sistema em um compilador de hardware ou ferramenta para síntese de alto nível $\left(\mathrm{HLS}^{4}\right)$.

Na Figura 5.11 é apresentado um diagrama de blocos que representa a arquitetura do módulo de geração de endereços, capaz de obter alto desempenho com mínimo overhead interno. Este módulo representa os loops aninhados da aplicação principal (sem reutilização de dados).

Assim como em (Menotti et al., 2009), a implementação do módulo para geração de endereços é baseada em contadores. Os mesmos estão conectados, produzindo os índices necessários para as operações realizada durante a composição dos endereços.

Na Figura 5.12 é apresentado o diagrama de blocos que representa o módulo gerador de endereços secundário, representado a função load( ), descrita na seção anterior. A arquitetura de hardware deste módulo é fixa, sempre contendo dois contadores (Counter for $_{\text {). }}$.

\footnotetext{
${ }^{4}$ HLS - High-Level Synthesis
} 


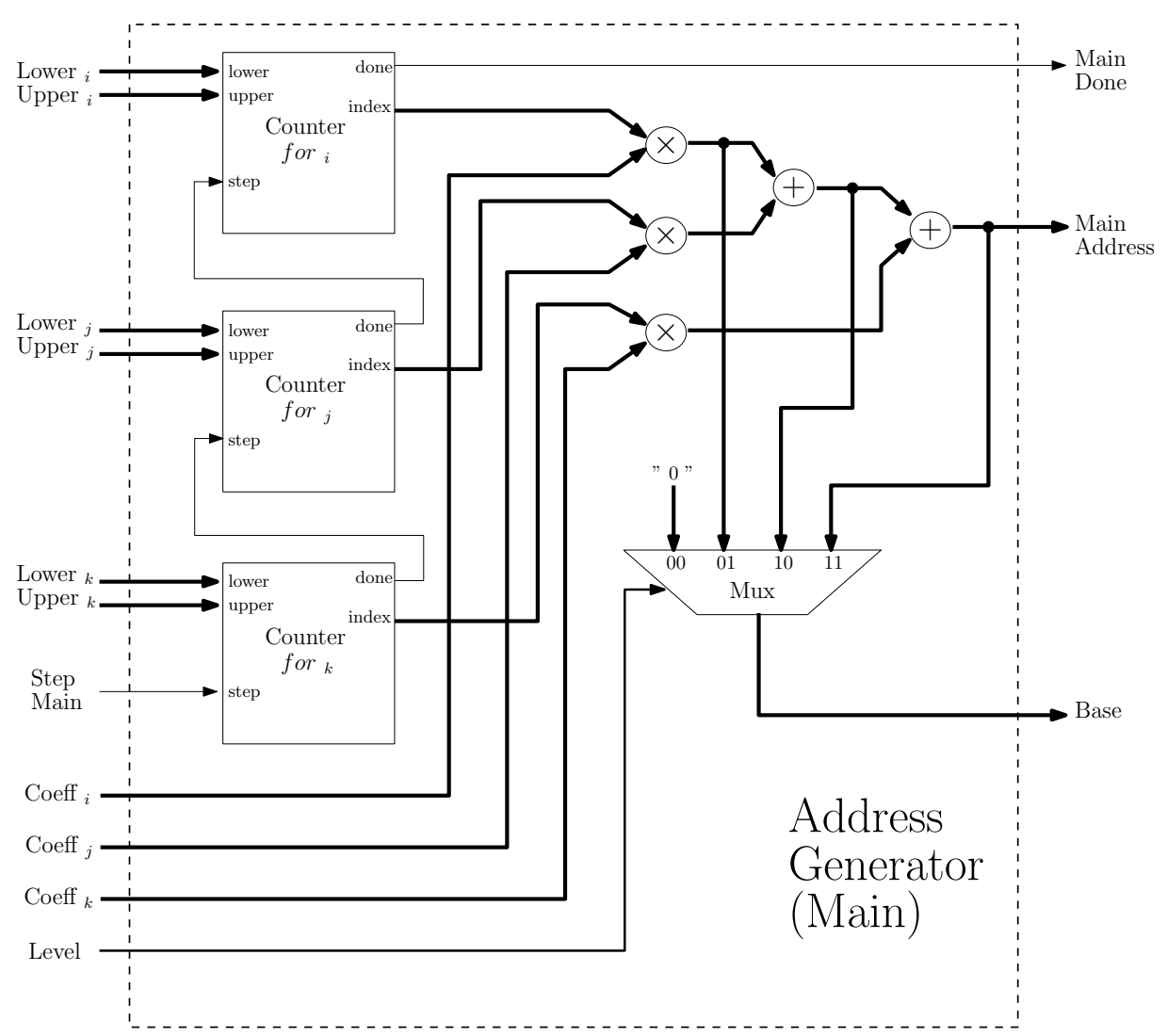

Figura 5.11: Diagrama de blocos do módulo para geração de endereços principal. Este representa a aplicação EM, com três loops aninhados indexados pelas variáveis $\mathrm{i}, \mathrm{j}$ e $\mathrm{k}$

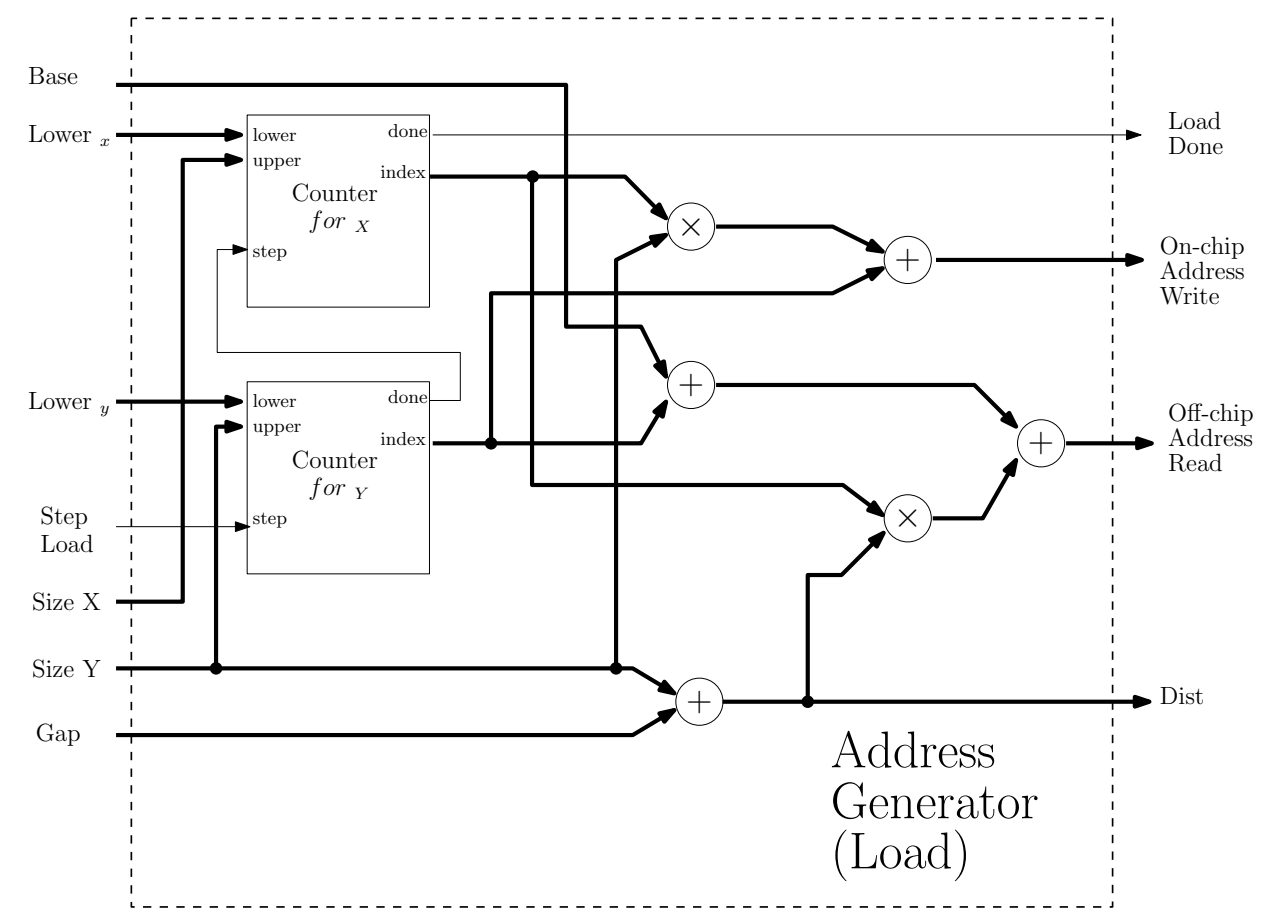

Figura 5.12: Diagrama de blocos do módulo para geração do endereços segundário, que representa a função load( ). 
A SPM é um caminho para expressar o padrão encontrado pela técnica, permitindo ao projetista definir exatamente quais dados trazer para a memória onchip, enquanto que em um sistema contendo uma cache tradicional esta definição seria baseada nas localidades espacial e temporal.

Na Figura 5.13 é apresentado o diagrama de blocos que representa o módulo para verificação e mapeamento de endereços, representando a função check( ), descrita na seção anterior. Assim como na implementação em software, este módulo precisa das operações mod e div. Estas operações costumam consumir muitos recursos lógicos do dispositivo, logo alternativas devem ser estudas para substituir tais elementos na implementação.

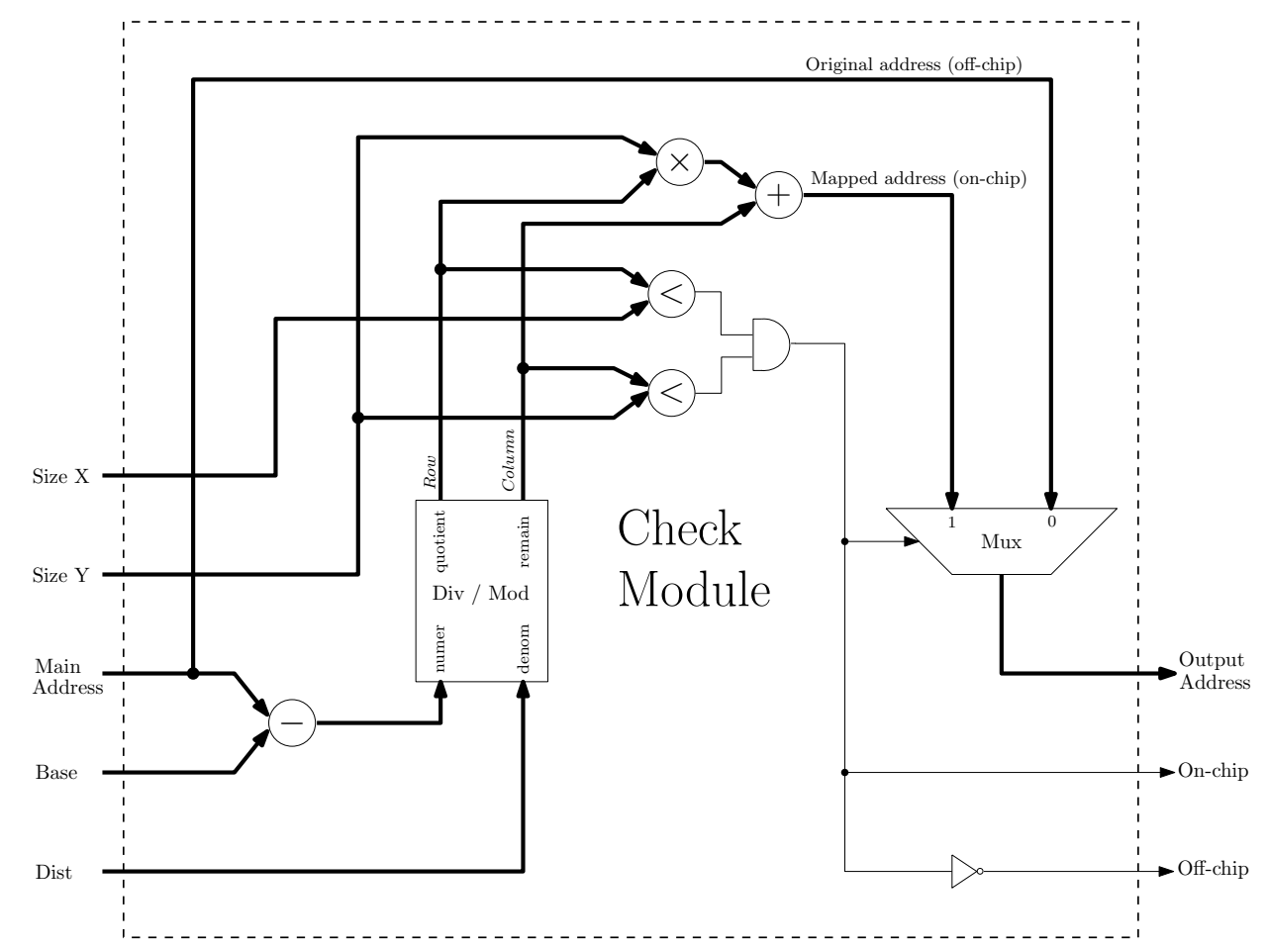

Figura 5.13: Diagrama de bloco do módulo de verificação e mapeamento, que representa a função check( ).

Junto com a SPM , o projetista precisa incluir um módulo de hardware para verificar se um determinado dados está on-chip ou não. Este módulo é necessário para a solução ótima local, uma vez que apenas um subconjunto dos dados utilizados pela aplicação está on-chip de uma só vez . Para a solução ótima global, que usa como o tamanho de memória necessário para a aplicação, esta função de verificação não é necessária , uma vez que garantidamente que não haverá erros.

Como pode ser observado na Figura 5.3, as operações mais complexas para a implementação do módulo de verificação de hardware são as operações mod e div, já que as outras operações são basicamente comparações. Nós implemen- 
tamos este módulo de hardware para o caso de uso Sobel para um FPGA Altera EP2C35F672C6, foi necessário aproximadamente 1300 de elementos lógicos, incluindo um controlador de SDRAM, e alcançou o frequência do requerida de 100 $\mathrm{MHz}$, previamente definida. O módulo de verificação introduz um custo adicional em relação aos recursos de hardware e pode afetar a freqüência de clock máxima operacional.

Na Tabela ?? são apresentados os principais resultados relacionados com a implementação da aplicação Sobel (144 x 176) de hardware.

Tabela 5.3: Elementos lógicos (LEs) e a frequência máxima (FMax) para a arquitetura Sobel.

\begin{tabular}{lcc}
\hline Module & LEs & FMax (MHz) \\
\hline Datapath & 140 & 97 \\
SDRAM Controller & 233 & 133 \\
Address Generator(Load) & 66 & 183 \\
Address Generator(Main) & 281 & 209 \\
Check & 605 & 55 \\
\hline System & 1325 & 107 \\
hline & &
\end{tabular}

Portanto, a implementação deste módulo precisa ser eficiente para reduzir esse overhead. Existem soluções para atenuar o custo de desenvolvimento do módulo de divisão (Miranda et al., 2001), que mostra uma forma simplificada das operações. Além disso, o AG poderia ser modificado para dar mais peso às configurações com a distância $\log _{2}$, evitando a operação de divisão utilizando a operação shift. Estes resultados poderiam ser melhorados com a introdução de novas capacidades de operações aritméticas fornecidas pelo estado da arte dos FPGAs. 


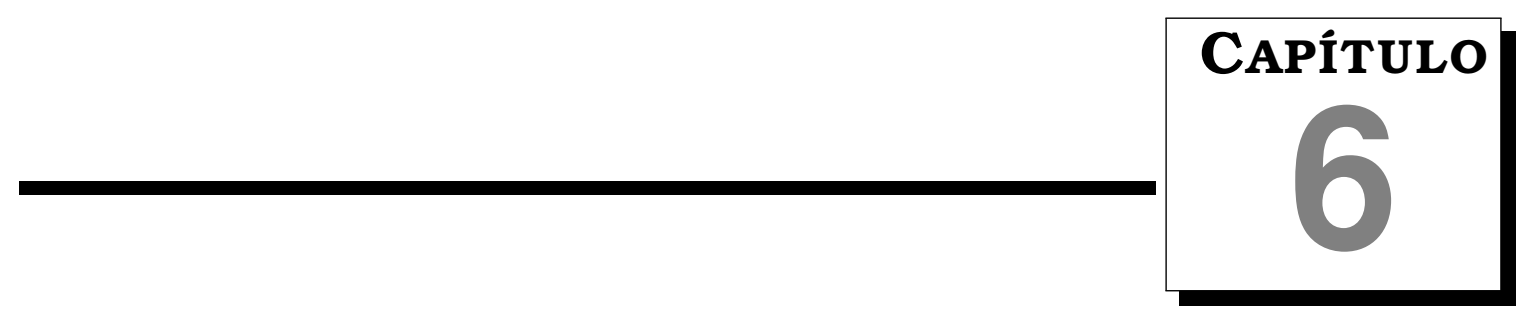

\section{Conclusões}

Esta dissertação apresentou uma técnica simples e efetiva para minimizar o número de acessos à memória off-chip utilizando um Algoritmo Genético (AG). Para tal, foi desenvolvida uma codificação específica baseada em um modelo que simula o comportamento de uma arquitetura de hardware.

O trabalho mostrou a efetividade dos AGs para a exploração do espaço de projetos para a reutilização de dados on-chip. O AG foi capaz de encontrar as melhores opções para reutilização de dados, gerando configurações que reduzem significativamente o número de acessos à memória off-chip e consomem uma quantidade mínima de recursos de memória on-chip. Diferente dos trabalhos relacionados (Liu et al., 2006, 2007), a abordagem permite a exploração de todo o espaço de busca e considera restrições de memória inseridas pelo usuário.

Adicionamente, o método pode ser utilizado em aplicações contendo loops regulares ou irregulares, além de possibilitar a geração de soluções válidas para aplicações com diferentes padrões de acesso à memória. Para validação da proposta, foi desenvolvida uma arquitetura de hardware customizada para a reutilização de dados em blocos de memória on-chip (BRAM).

\subsection{Trabalhos Futuros}

O sucesso da abordagem evolutiva (AG), mostrado neste trabalho, motiva a exploração de espaços de busca cada vez mais complexos. Além disso, durante o desenvolvimento imergiram várias questões sobre as limitações da abordagem 
e idéias sobre quais pontos podem ser oportunidades para trabalhos futuros. As sugestões incluem melhorias da técnica e a adição de novas característas ao sistema (hardware/software). Dentre estas, destacam-se:

- Considerar simultaneamente os carregamentos (load( )) e os armazenamentos (store( ));

- Permitir carregamentos e armazenamentos cooperativos entre os níveis de loop;

- Eliminar as redundâncias entre carregamentos consecutivos;

- Trabalhar com aplicações de indexação não linear (non-affine);

- Considerar a otimização de toda uma aplicação (não somente de kernels);

- Desenvolver uma técnica baseada em profiling para identificação automática dos trechos críticos;

- Considerar a reutilização de dados para arquiteturas contendo várias unidades de processamento (paralelismo);

- Aplicar técnicas de otimização multi-objetivo para exploração do espaço de projeto para reutilização de dados;

- Gerar automáticamente as arquiteturas de hardware otimizadas para reutilização de dados de on-chip. 


\section{Referências Bibliográficas}

ABSAR, M. J.; CATTHOOR, F. Compiler-based approach for exploiting scratchpad in presence of irregular array access. In: Design, Automation and Test in Europe, 2005. Proceedings, IEEE, 2005, p. 1162-1167.

Ashenden, P. Digital design: an embedded systems approach using vhdl. Morgan Kaufmann. Elsevier/Morgan Kaufmann Publishers, 2008.

BARAdARAN, N.; PARK, J.; Diniz, P. Compiler reuse analysis for the mapping of data in fpgas with ram blocks. In: Field-Programmable Technology, 2004. Proceedings. 2004 IEEE International Conference on, 2004, p. 145 - 152.

Bayliss, S.; Constantinides, G. A. Optimizing sdram bandwidth for custom fpga loop accelerators. In: Proceedings of the ACM/SIGDA international symposium on Field Programmable Gate Arrays, FPGA '12, New York, NY, USA: ACM, 2012, p. 195-204 (FPGA '12, ).

BOBDA, C. Introduction to reconfigurable computing: architectures, algorithms, and applications. Springer, 2007.

CARDOSO, J.; DINIZ, P. Compilation techniques for reconfigurable architectures. Sitzungsberichte der Heidelberger Akademie der Wissenschaften, Mathematisch-Naturwissenschaftliche Klasse. Springer, 2008.

CATTHOOR, F.; DANCKART, K. Data access and storage management for embedded programmable processors. Kluwer Academic, 2002.

Catthoor, F.; Greef, E. D.; Suytack, S. Custom memory management methodology: Exploration of memory organisation for embedded multimedia system design. Norwell, MA, USA: Kluwer Academic Publishers, 1998.

Compton, K.; Hauck, S. Reconfigurable computing: a survey of systems and software. ACM Comput. Surv., New York, NY, USA: ACM, v. 34, n. 2, p. 171210, Jun., 2002.

Darte, A.; Schreiber, R.; Villard, G. Lattice-based memory allocation. Computers, IEEE Transactions on, v. 54, n. 10, p. 1242-1257, Oct., 2005.

DARWIN, C. On the origin of species. London: John Murray, 1859, 502 p.. 
DEB, K. Multi-objective optimization using evolutionary algorithms. Wiley-Interscience series in systems and optimization. John Wiley \& Sons, 2001.

DEB, K.; AGrawAL, R. B. Simulated binary crossover for continuous search space. Complex Systems, Citeseer, v. 9, p. 1-34, xxx, 1994.

DEB, K.; AGRAWAL, S. A niched-penalty approach for constraint handling in genetic algorithms. In: Artificial Neural Nets and Genetic Algorithms. Springer Vienna, 1999. p. 235-243.

Disponivel em: <http://dx.doi.org/10.1007/978-3-7091-6384-9_40>.

Devos, H.; Van Campenhout, J.; Verbauwhede, I.; Stroobandt, D. Transactions on high-performance embedded architectures and compilers iii. Berlin, Heidelberg: Springer-Verlag, 2011a. c cÃip. Constructing applicationspecific memory hierarchies on FPGAs, p. 201-216.

Disponivel em: <http://dl.acm.org/citation.cfm?id=1980776. $1980790>$.

Devos, H.; Van Campenhout, J.; Verbauwhede, I.; Stroobandt, D. Transactions on high-performance embedded architectures and compilers iii. Berlin, Heidelberg: Springer-Verlag, 2011b. cÃ ip. Constructing applicationspecific memory hierarchies on FPGAs, p. 201-216.

Disponivel em: <http://dl.acm.org/citation.cfm?id=1980776. $1980790>$.

FInGEROFF, M. High-level synthesis blue book. Xlibris Corporation, 2010.

GoldBerG, D. E. Genetic algorithms in search, optimization, and machine learning. Boston: Addison-Wesley Professional, 1989, 432 p..

Hamblen, J.; Hall, T.; Furman, M. Rapid prototyping of digital systems. Springer, 2008.

HAUCK, S.; DEHON, A. Reconfigurable computing: the theory and practice of fpga-based computation. Systems on Silicon. Morgan Kaufmann, 2008.

HAUPT, R.; HAUPT, S. Practical genetic algorithms. Wiley-Interscience publication. John Wiley, 2004.

Hennessy, J. L.; Patterson, D. A. Computer architecture, fifth edition: A quantitative approach. 5th ed. San Francisco, CA, USA: Morgan Kaufmann Publishers Inc., 2011.

Holland, J. H. Adaptation in natural and artificial systems. Michigan: The University of Michigan Press, 1975.

Issenin, I.; Brockmeyer, E.; Miranda, M.; DutT, N. Data reuse analysis technique for software-controlled memory hierarchies. In: Design, Automation and Test in Europe Conference and Exhibition, 2004. Proceedings, 2004, p. $202-207$ Vol. 1. 
JACOB, B.; NG, S.; WANG, D. Memory systems: cache, dram, disk. Morgan Kaufmann, 2007.

Jong, K. A. D. Evolutionary computation : A unified approach. Cambridge: MIT Press, 2006, 256 p..

KAndemir, M.; KADAYIF, I.; Sezer, U. Exploiting scratch-pad memory using presburger formulas. In: System Synthesis, 2001. Proceedings. The 14th International Symposium on, 2001, p. $7-12$.

KANDEMIR, M.; RAMANUJAM, J.; IRWIN, M.; VIJAYKRISHNAN, N.; KADAYIF, I.; PARIKH, A. A compiler-based approach for dynamically managing scratchpad memories in embedded systems. Computer-Aided Design of Integrated Circuits and Systems, IEEE Transactions on, v. 23, n. 2, p. 243-260, Feba, 2004a.

KANDEMIR, M.; RAMANUJAM, J.; IRWIN, M. J.; ViJAYKRISHNAN, N.; KADAYIF, I.; PARIKH, A. A compiler-based approach for dynamically managing scratch-pad memories in embedded systems. v. 23, n. 2, p. 243-260, ????b, 2004b.

Kastner, R.; Hosangadi, A.; Fallah, F. Arithmetic optimization techniques for hardware and software design. Arithmetic Optimization Techniques for Hardware and Software Design. Cambridge University Press, 2009.

KHAN, S. Digital design of signal processing systems: A practical approach. John Wiley \& Sons, 2011.

Klopfenstein, L. C. Klopfenstein.net. Acessado em 20/01/2012, 2012.

Disponivel em: <http://www.klopfenstein.net/lorenz.aspx/ genetic-algorithms>.

LIU, Q. Data reuse and parallelismin hardware compilation. 2008a. Doctoral thesis, Imperial College London, 2008a.

LIU, Q. Data reuse and parallelismin hardware compilation. 2008b. Doctoral thesis, Imperial College London, 2008b.

Liu, Q.; Constantinides, G.; Masselos, K.; Cheung, P. Automatic on-chip memory minimization for data reuse. In: Field-Programmable Custom Computing Machines, 2007. FCCM 2007. 15th Annual IEEE Symposium on, 2007, p. $251-260$.

Liu, Q.; Constantinides, G.; Masselos, K.; Cheung, P. Combining data reuse with data-level parallelization for fpga-targeted hardware compilation: A geometric programming framework. Computer-Aided Design of Integrated Circuits and Systems, IEEE Transactions on, v. 28, n. 3, p. 305-315, Mar.a, 2009a.

Liu, Q.; Constantinides, G. A.; Masselos, K.; Cheung, P. Combining data reuse with data-level parallelization for fpga-targeted hardware compilation: A geometric programming framework. v. 28, n. 3, p. 305-315, ????b, 2009b. 
Liu, Q.; Masselos, K.; Constantinides, G. Data reuse exploration for fpga based platforms applied to the full search motion estimation algorithm. In: Field Programmable Logic and Applications, 2006. FPL '06. International Conference on, 2006, p. $1-6$.

MenotTi, R. Lalp: uma linguagem para exploração do paralelismo de loops em computação reconfigurável. 2010. Tese de doutorado, Instituto de Ciências Matemáticas e de Computação, ICMC/USP, São Carlos, SP, 2010.

Menotti, R.; Cardoso, J. M. P.; Fernandes, M. M.; Margues, E. Lalp: A novel language to program custom fpga-based architectures. In: Proc. 21st Int. Symp. Computer Architecture and High Performance Computing SBAC-PAD'09, 2009, p. 3-10.

Miranda, M.; Ghez, C.; Kulkarni, C.; Catthoor, F.; Verkest, D. Systematic speed-power memory data-layout exploration for cache controlled embedded multimedia applications. In: System Synthesis, 2001. Proceedings. The 14th International Symposium on, 2001, p. 107-112.

PANDA, P.; DUTT, N.; NicOlaU, A. Memory issues in embedded systems-onchip: Optimizations and exploration. Kluwer Academic, 1999.

PANDA, P. R.; DUTT, N. D.; Nicolau, A. On-chip vs. off-chip memory: the data partitioning problem in embedded processor-based systems. ACM Trans. Des. Autom. Electron. Syst., New York, NY, USA: ACM, v. 5, p. 682-704, Jul., 2000.

PERRY, D. Vhdl: programming by example. McGraw-Hill, 2002.

Pouchet, L.-N.; Zhang, P.; Sadayappan, P.; Cong, J. Polyhedral-based data reuse optimization for configurable computing. In: Proceedings of the ACM/SIGDA international symposium on Field programmable gate arrays, FPGA '13, New York, NY, USA: ACM, 2013, p. 29-38 (FPGA '13, ).

Reeves, C.; Rowe, J. Genetic algorithms: principles and perspectives : a guide to ga theory. Operations research/computer science interfaces series. Kluwer Academic Publishers, 2003.

SIVANANDAM, S. N.; DEEPA, S. N. Introduction to genetic algorithms. 1st ed. Springer Publishing Company, Incorporated, 2007.

SystemC Acessado em 15/01/2012, 2012.

Disponível em: <http://www.accellera.org/home/>.

Tessier, R.; Burleson, W. Reconfigurable computing for digital signal processing: A survey. The Journal of VLSI Signal Processing, Springer Netherlands, v. 28, p. 7-27, May, 2001.

Verma, M.; Steinke, S.; Marwedel, P. Data partitioning for maximal scratchpad usage. In: Design Automation Conference, 2003. Proceedings of the ASP-DAC 2003. Asia and South Pacific, 2003, p. 77-83. 